\title{
Comparative assessment of validity of gradient wind models for a translating tropical cyclone
}

\author{
Yuzuru Eguchi $^{1}$ [D $\cdot$ Yasuo Hattori ${ }^{1} \cdot$ Mitsuharu Nomura ${ }^{1}$
}

Received: 5 November 2020 / Accepted: 18 February 2021 / Published online: 2 March 2021

(c) The Author(s) 2021 OPEN

\begin{abstract}
Accurate and conservative evaluations of the gradient wind in the free atmosphere are needed to account for high-wind hazards when designing wind resistance for critical infrastructure. This paper compared the validity of three existing gradient wind models to select an appropriate evaluation model, which enables us to accurately compute the asymmetric gradient wind field of a translating tropical cyclone under the condition of a symmetric pressure distribution and a constant translation velocity. The validity of the three models was assessed by evaluating the residuals in momentum conservation equations for the gradient wind under a specific tropical cyclone condition. The magnitude of the residuals was considered to be the measure of error in the gradient wind derived from each model. The results showed that the most frequently used model yielded the largest magnitude of residuals with the lowest maximum wind speed among the three models. The wind characteristics of the three models were validated using archived observation data of hurricanes. The physical reason for the difference in maximum wind speed among the three models was explained by the difference in the streamline feature of the gradient wind field. It was also revealed that the differences in maximum wind speed and magnitude of residuals became more pronounced as the translation speed and the intensity of a tropical cyclone increased. The comparative assessment of the three gradient wind models allowed us to identify the best model for use in conservative wind-resistant design and high-wind risk estimates.
\end{abstract}

Keywords Tropical cyclone $\cdot$ Translation · Gradient wind model $\cdot$ Validity $\cdot$ Momentum equation $\cdot$ Residual

\section{Introduction}

Tropical cyclones, known as hurricanes or typhoons, cause a variety of hazards such as high winds, heavy rainfall, flooding and tidal surges. High winds alone can cause damage that has a significant socioeconomic impact on local communities. Appropriate wind-resistant design is needed to withstand the high-wind hazard imposed on infrastructure, especially for critical facilities such as nuclear power plants and transmission lines. The most commonly used tool for the estimation of wind loads and wind-borne missile speeds is a tropical cyclone hazard model [1-5], which allows us to estimate the maximum wind speed and direction expected for a given return period. In such a model, the accurate and conservative evaluation of the gradient wind in the free atmosphere is a critical component; this is because the surface wind speed and direction at $10 \mathrm{~m}$ above the ground are often deduced from the gradient wind either using an atmospheric boundary layer model [6-11] or simply by multiplying the gradient wind vector by an estimated reduction factor $[12,13]$.

The gradient wind is usually assumed to be parallel to the tangential direction of isobars, with its magnitude being regulated by a balance of the Coriolis, pressure gradient, and centrifugal forces. A gradient wind model is

Yuzuru Eguchi, eguchi@criepi.denken.or.jp| ${ }^{1}$ Civil Engineering Research Laboratory, Central Research Institute of Electric Power Industry, 1646, Abiko-shi, Chiba-ken, Abiko 270-1194, Japan. 
theoretically considered to work well for steady winds in the middle and upper troposphere above the atmospheric boundary layer, where the frictional effect from surface drag is negligible. Although gradient wind models are also applied when evaluating the gradient wind field of an unsteady translating tropical cyclone by assuming a symmetrical pressure distribution and a constant translation velocity, the validity of gradient wind models for translating tropical cyclones is still not well understood. A good gradient wind model for a translating tropical cyclone should be able to accurately reproduce the asymmetry of the wind field such that a maximum wind speed appears to the right of the cyclone translation direction in the Northern Hemisphere, and to the left in the Southern Hemisphere. One of the most common models for the gradient wind field in a translating tropical cyclone is the one used by Georgiou [14] and others [6, 7, 10, 11, 15-17]. We hereafter refer to this model as "Georgiou's model" in accordance with the convention in recent literature [12, $15,17]$. The key assumption of Georgiou's model is that the streamline curvature of the gradient wind should be the same as the isobar line curvature. However, such an assumption is not always justified because streamline curvature can deviate from isobar curvature, as rigorously explained by Brill [18] for general synoptic-scale conditions.

In the present study, to assess the validity of Georgiou's model for a translating tropical cyclone, we compared it with two models, proposed by Yoshizumi [19] and Wang et al. [12]. The residuals in the momentum conservation equations for the gradient wind fields of the three models were evaluated for a specific cyclone condition. Then, the results were analyzed to examine the characteristics of the gradient wind fields and the residuals of the three models. These characteristics were also validated using observation data of Hurricanes Emily (July 2005) and Wilma (October 2005), archived in the Tropical Cyclone Observing System, $\mathrm{H}^{*}$ WIND [20]. The three models are outlined in Sect. 2, and the residual evaluation methods and results are shown in Sect. 3. Validation of the models using the observation data is presented in Sect. 4. Section 5 is devoted to a discussion of the characteristic features of the three models, such as wind speed tendency, streamline curvatures, and sensitivities to tropical cyclone parameters. The concluding remarks are contained in the final section.

\section{Outline of gradient wind models}

In the following three gradient wind models of a translating tropical cyclone, the pressure distribution is assumed to be axisymmetric and to translate at a constant speed and direction in a two-dimensional (2D) domain, along with the gradient wind field. In this paper, the constant translation velocity vector is denoted by $\mathbf{C}=\left(c_{x}, c_{y}\right)^{\top}$, and the pressure distribution, $p(r)$, proposed by Holland [21], is presumed to be a function of radius, $r$, as shown below:

$p(r)=p_{0}+\Delta p \exp \left(-\left(\frac{r_{m}}{r}\right)^{B}\right)$

where $p_{0}, \Delta p, r_{m}$ and $B$ stand for pressure at center, pressure difference between center and infinity, nominal radius to maximum wind speed, and Holland's $B$-parameter, respectively. These values are assumed to be constant in this paper, although they can be treated as variables to derive a wind field empirically by incorporating surface observation data [22-25]. The center of the pressure distribution (or a translating tropical cyclone) is assumed to be located at the origin of the earth-fixed Cartesian coordinates at time, $t=0$.

In the subsequent parts of this paper, the Coriolis parameter, $f$, is assumed to be constant in the limited area of the Northern Hemisphere concerned. The Coriolis parameter, $f$, is represented as shown below, using the sidereal rotation frequency of the earth, $\Omega$, and the latitude at the center of the pressure distribution in the Northern Hemisphere $\varphi_{0}$

$f=2 \Omega \sin \varphi_{0}$

\subsection{Georgiou's model}

Georgiou [14] used the following equation of balance between the centrifugal force, the Coriolis force, and the pressure gradient force:

$$
-\frac{V_{g}^{2}}{R_{p}}-f V_{g}+\frac{1}{\rho} \frac{\partial p}{\partial r}=0
$$

where $V_{g}$ and $\rho$ stand for the magnitude of the gradient wind and the density of the air, respectively. The radii of curvature of the air parcel path lines, $R_{p}$, in Georgiou's model are usually computed based on Blaton's formula, which states the relationship between the radius of curvature of path line, $R_{p}$, the radius of curvature of streamline, $R_{S}$ and the temporal rate of wind direction variation [26] as shown below:

$\frac{1}{R_{P}}=\frac{1}{R_{S}}-\frac{1}{V_{g}} \frac{\partial \psi}{\partial t}$

where $\psi$ denotes the conventional meteorological wind direction of the gradient wind, positive in a clockwise direction measured from the north. The temporal differentiation of $\psi$ can be evaluated with the translation speed, 
$C=|\mathbf{C}|$, as follows, considering geometrical relations such as $\psi=\gamma+a+\pi / 2, r^{2}=\left(x-c_{x} t\right)^{2}+\left(y-c_{y} t\right)^{2}$ and $\sin (\psi-\pi)=\left(y-c_{y} t\right) / r$, as shown in Fig. 1:

$\frac{\partial \psi}{\partial t}=\frac{\partial \alpha}{\partial t}=\frac{C \sin \alpha}{r}$

The key assumption of Georgiou's model is that the radius of curvature of streamline, $R_{S}$, should be the same as that of the isobar line, $r$. Then, the gradient wind velocity vector, $\mathbf{V}_{g}=\left(V_{x}, V_{y}\right)^{\top}$ at time, $t=0$, can be derived as follows using Eq. (3) along with Eqs. (4) and (5):

$\mathbf{v}_{g}=\left(\begin{array}{c}-V_{g} \cos (\gamma+\alpha) \\ V_{g} \sin (\gamma+\alpha)\end{array}\right)=\left(\begin{array}{c}-\frac{V_{g} y}{v_{g}^{r}} \\ \frac{V_{g}}{r}\end{array}\right)$

where the magnitude of the gradient wind, $V_{g}$, is given below:

$V_{g}=\frac{C \sin \alpha-f r}{2}+\sqrt{\left(\frac{C \sin \alpha-f r}{2}\right)^{2}+\frac{r}{\rho} \frac{\partial p}{\partial r}}$

It should be noted that Meng et al. [6] derived a gradient wind velocity identical to Eq. (6) from the radial momentum conservation equation in the axisymmetric coordinates moving with a tropical cyclone.

The spatial derivatives of the gradient wind velocity, $\mathbf{V}_{g}=\left(V_{x}, V_{y}\right)^{\top}$, for Georgiou's model at a point $(x, y)$ at time, $t=0$, can be derived as follows with $r^{2}=x^{2}+y^{2}$, and these are used to compute residuals in Sect. 3 .

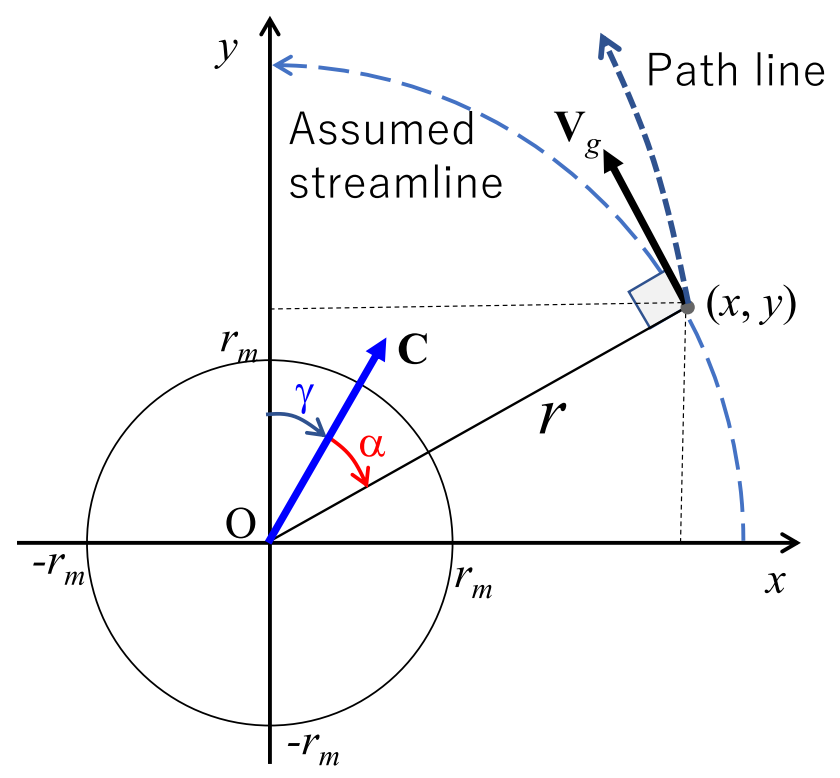

Fig. 1 Geometry and an assumed streamline of Georgiou's model $\frac{\partial V_{x}}{\partial x}=\frac{x y}{r^{3}} V_{g}-\frac{y}{r} \frac{\partial V_{g}}{\partial x}$

$\frac{\partial V_{x}}{\partial y}=\frac{y^{2}}{r^{3}} V_{g}-\frac{V_{g}}{r}-\frac{y}{r} \frac{\partial V_{g}}{\partial y}$

$$
\frac{\partial V_{y}}{\partial x}=-\frac{x^{2}}{r^{3}} V_{g}+\frac{V_{g}}{r}+\frac{x}{r} \frac{\partial V_{g}}{\partial x}
$$

$\frac{\partial V_{y}}{\partial y}=-\frac{x y}{r^{3}} V_{g}+\frac{x}{r} \frac{\partial V_{g}}{\partial y}$

In the above, $V_{g}$ is presented by Eq. (7), while the derivatives are given as follows.

$\frac{\partial V_{g}}{\partial x}=\frac{-f V_{g} \frac{x}{r}+\left(-\frac{c_{y} x^{2}}{r^{3}}+\frac{c_{y}}{r}+\frac{c_{x} x y}{r^{3}}\right) V_{g}+\frac{x}{\rho r} \frac{\partial p}{\partial r}+\frac{x}{\rho} \frac{\partial^{2} p}{\partial r^{2}}}{2 V_{g}+f r-\left(\frac{c_{y} x}{r}-\frac{c_{x} y}{r}\right)}$

$\frac{\partial V_{g}}{\partial y}=\frac{-f V_{g} \frac{y}{r}+\left(\frac{c_{X} y^{2}}{r^{3}}-\frac{c_{x}}{r}-\frac{c_{y} X y}{r^{3}}\right) V_{g}+\frac{y}{\rho r} \frac{\partial p}{\partial r}+\frac{y}{\rho} \frac{\partial^{2} p}{\partial r^{2}}}{2 V_{g}+f r-\left(\frac{c_{y} X}{r}-\frac{c_{x} y}{r}\right)}$

where the first and second derivatives of pressure, $p$, with respect to $r$ in Eqs. (12) and (13) are given as follows for the Holland's pressure distribution described by Eq. (1).

$\frac{\partial p}{\partial r}=\frac{B \Delta p r_{m}^{B}}{r^{B+1}} \exp \left(-\left(\frac{r_{m}}{r}\right)^{B}\right)$

$\frac{\partial^{2} p}{\partial r^{2}}=\frac{B \Delta p r_{m}^{B}}{r^{B+2}}\left(\frac{B r_{m}^{B}}{r^{B}}-B-1\right) \exp \left(-\left(\frac{r_{m}}{r}\right)^{B}\right)$

\subsection{Yoshizumi's model}

Yoshizumi [19] developed a gradient wind model, based on the horizontal momentum conservation equation described in the coordinates moving with a tropical cyclone, and showed that the gradient wind velocity, $\mathbf{V}_{g}$, in the earth-fixed coordinates can be approximated by the following relationship:

$\mathbf{v}_{g}=\mathbf{v}_{g 0}+\frac{K}{K+1} \mathbf{C}$

where $\mathbf{V}_{g 0}$ is the axisymmetric gradient wind vector for zero translation speed, whose magnitude, $V_{g 0}$, is given by the following equation: 
$V_{g 0}=-\frac{1}{2} f r+\sqrt{\left(\frac{1}{2} f r\right)^{2}+\frac{r}{\rho} \frac{\partial p}{\partial r}}$

In Eq. (16), $K$ is defined as the ratio of the centrifugal force to the Coriolis force, expressed below as:

$K=\frac{V_{g 0}}{f r}=-\frac{1}{2}+\sqrt{\left(\frac{1}{2}\right)^{2}+\frac{1}{f^{2} r \rho} \frac{\partial p}{\partial r}}$

As seen in Eq. (18), $K$ depends on radius, $r$, and the pressure gradient. Figure 2 shows the distribution of $K$ with variation in the normalized radius, $r / r_{m}$, for Holland's pressure distribution expressed by Eq. (1) and Fujita's pressure distribution [27] expressed below as:

$p(r)=p_{0}+\Delta p\left(1-\frac{1}{\sqrt{1+2\left(r / r_{m}\right)^{2}}}\right)$

Figure 2 indicates that the coefficient for $\mathbf{C}$ in Eq. (16), $K /(K+1)$, tends to approach unity near the center, while it decreases to zero in regions far from the center. This indicates that the gradient wind, $\mathbf{v}_{g}$, can be approximated by the sum of the axisymmetric gradient wind, $\mathbf{V}_{g 0}$, and the translation velocity, $\mathbf{C}$, near the center, while the gradient wind, $\mathbf{V}_{g}$, approaches the axisymmetric gradient wind, $\mathbf{V}_{g 0}$, in regions far from the center.

In summary, the components of the approximated gradient wind velocity, $\mathbf{V}_{g}=\left(V_{x}, V_{y}\right)^{\top}$ at time, $t=0$, are described as below in accordance with Eq. (16):

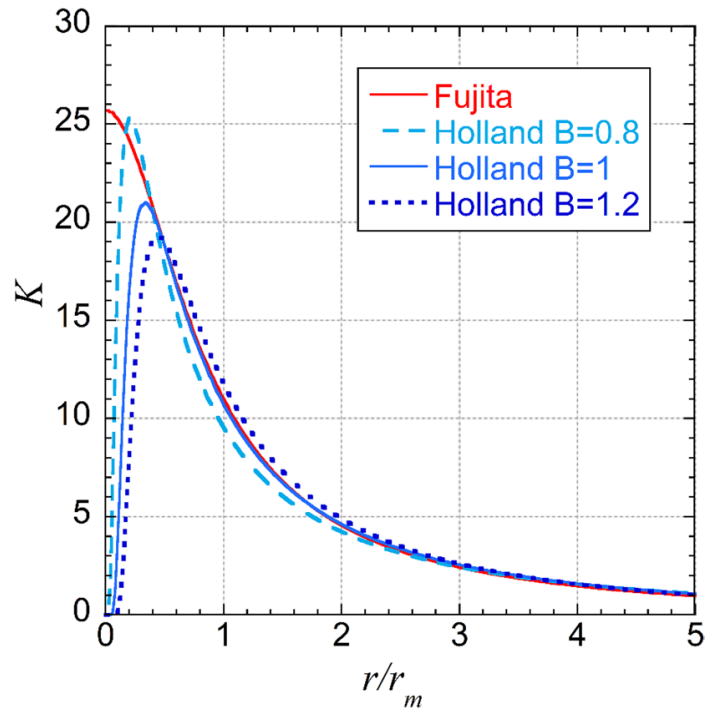

Fig. $2 \mathrm{~K}$-value used in Yoshizumi's model with variation in normalized radius

SN Applied Sciences
$\mathbf{V}_{g}=\left(\begin{array}{c}-\frac{V_{g 0} y}{r}+\frac{c_{x} K}{K+1} \\ \frac{V_{g 0} x}{r}+\frac{c_{y} K^{1}}{K+1}\end{array}\right)$

The spatial derivatives of gradient wind velocity, $\mathbf{V}_{g}=\left(V_{x}, V_{y}\right)^{\top}$, for Yoshizumi's model at time, $t=0$, can be derived as follows, and these are used to compute residuals in Sect. 3.

$\frac{\partial V_{x}}{\partial x}=\frac{x y}{r^{3}}\left(V_{g 0}-r \frac{\partial V_{g 0}}{\partial r}\right)+c_{x} \frac{\partial F}{\partial x}$

$\frac{\partial V_{x}}{\partial y}=\frac{y^{2}}{r^{3}}\left(V_{g 0}-r \frac{\partial V_{g 0}}{\partial r}\right)-\frac{V_{g 0}}{r}+c_{x} \frac{\partial F}{\partial y}$

$\frac{\partial V_{y}}{\partial x}=\frac{x^{2}}{r^{3}}\left(-V_{g 0}+r \frac{\partial V_{g 0}}{\partial r}\right)+\frac{V_{g 0}}{r}+c_{y} \frac{\partial F}{\partial x}$

$\frac{\partial V_{y}}{\partial y}=\frac{x y}{r^{3}}\left(-V_{g 0}+r \frac{\partial V_{g 0}}{\partial r}\right)+c_{y} \frac{\partial F}{\partial y}$

In the above, $V_{g 0}$ is presented by Eq. (17) and $F$ is defined by $F=K /(1+K)$ with $K$ described by Eq. (18), while the derivatives are given as follows.

$\frac{\partial V_{g 0}}{\partial r}=\frac{-f V_{g 0}+\frac{1}{\rho} \frac{\partial p}{\partial r}+\frac{r}{\rho} \frac{\partial^{2} p}{\partial r^{2}}}{2 V_{g 0}+f r}$

$\frac{\partial F}{\partial x}=(K+1)^{-2} \frac{\partial K}{\partial r} \frac{x}{r}$

$\frac{\partial F}{\partial y}=(K+1)^{-2} \frac{\partial K}{\partial r} \frac{y}{r}$

$\frac{\partial K}{\partial r}=\frac{1}{2 f^{2} r^{2} \rho}\left(K+\frac{1}{2}\right)^{-1}\left(-\frac{\partial p}{\partial r}+r \frac{\partial^{2} p}{\partial r^{2}}\right)$

The first and second derivatives of pressure, $p$, in Eqs. (25) and (28) are the same as Eqs. (14) and (15).

\subsection{Wang et al.'s model}

Wang et al. [12] proposed a model to estimate the gradient wind field. They assumed that the gradient wind vector, $\mathbf{V}_{g}$, is composed of a cyclone translating vector, $\mathbf{C}$, and an unknown rotational vector, $\mathbf{V}_{q}$, as shown below and in Fig. 3(a) and (b):

$\mathbf{V}_{g}=\mathbf{V}_{q}+\mathbf{C}$ 
Fig. 3 Geometry and vectors of Wang et al.'s model: a relationship between the translation vector, $\mathbf{C}$, and the rotational gradient wind, $\mathbf{v}_{q^{\prime}}$ and $\mathbf{b}$ composition of the gradient wind vector, $\mathbf{v}_{g}$

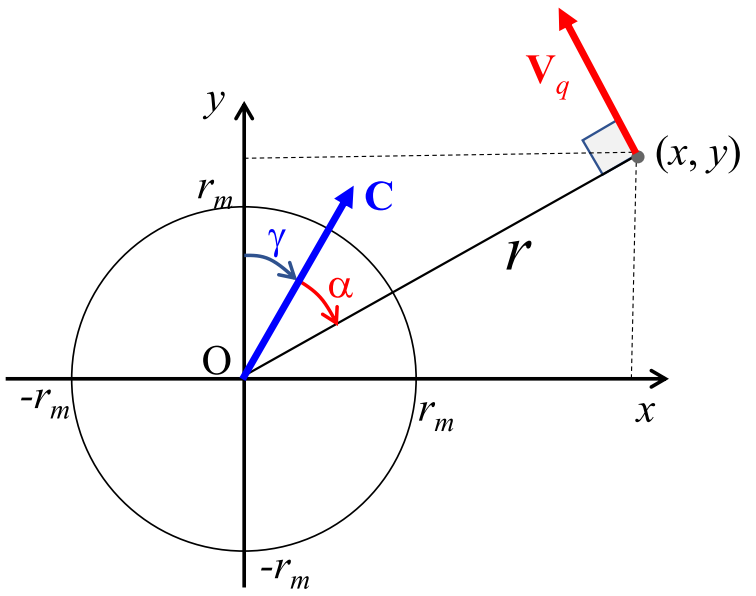

(a)

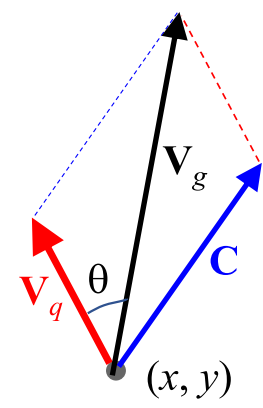

(b)
Then, the balance of the pressure gradient force, the centrifugal force and the Coriolis force was established as follows to seek the unknown vector, $\mathbf{V}_{q}$, with $\theta$ being the angle between the $\mathbf{V}_{g}$ and $\mathbf{V}_{q}$ vectors:

$-\frac{V_{q}^{2}}{r}-f V_{g} \cos \theta+\frac{1}{\rho} \frac{\partial p}{\partial r}=0$

where $V_{g}$ and $V_{q}$ denote the magnitudes of $\mathbf{v}_{g}$ and $\mathbf{v}_{q^{\prime}}$ respectively. A final form of the gradient wind vector, $\mathbf{V}_{g}=\left(V_{x}, V_{y}\right)^{\top}$ at time, $t=0$, is expressed as follows:

$\mathbf{v}_{g}=\left(\begin{array}{c}-\frac{v_{q} y}{v_{q}^{r}}+c_{x} \\ \frac{v^{r}}{r}+c_{y}\end{array}\right)$

where $V_{q}$ is given by the following equation:

$V_{q}=-\frac{1}{2} f r+\sqrt{\left(\frac{1}{2} f r\right)^{2}+\frac{r}{\rho} \frac{\partial p}{\partial r}-f r C \sin \alpha}$

The spatial derivatives of gradient wind velocity, $\mathbf{V}_{g}=\left(V_{x}, V_{y}\right)^{\top}$, for Wang et al's model at time, $t=0$, can be derived as follows, and these are used to compute residuals in Sect. 3:

$\frac{\partial V_{x}}{\partial x}=\frac{x y}{r^{3}} V_{q}-\frac{y}{r} \frac{\partial V_{q}}{\partial x}$

$\frac{\partial V_{x}}{\partial y}=\frac{y^{2}}{r^{3}} V_{q}-\frac{V_{q}}{r}-\frac{y}{r} \frac{\partial V_{q}}{\partial y}$

$\frac{\partial V_{y}}{\partial x}=-\frac{x^{2}}{r^{3}} V_{q}+\frac{V_{q}}{r}+\frac{x}{r} \frac{\partial V_{q}}{\partial x}$ $\frac{\partial V_{y}}{\partial y}=-\frac{x y}{r^{3}} V_{q}+\frac{x}{r} \frac{\partial V_{q}}{\partial y}$

In the above, the derivatives of $v_{q}$ are given in the following form:

$\frac{\partial V_{q}}{\partial x}=\frac{-\frac{x}{r} f V_{q}-f c_{y}+\frac{x}{\rho r} \frac{\partial p}{\partial r}+\frac{x}{\rho} \frac{\partial^{2} p}{\partial r^{2}}}{2 V_{q}+f r}$

$\frac{\partial V_{q}}{\partial y}=\frac{-\frac{y}{r} f V_{q}+f c_{x}+\frac{y}{\rho r} \frac{\partial p}{\partial r}+\frac{y}{\rho} \frac{\partial^{2} p}{\partial r^{2}}}{2 V_{q}+f r}$

The first and second derivatives of pressure, $p$, in Eqs. (37) and (38), are the same as Eqs. (14) and (15).

\section{Evaluation of the validity of gradient wind models}

\subsection{Evaluation method}

If the pressure distribution and gradient wind field translate along a constant vector, $\mathbf{C}$, the pressure and velocity should satisfy the following horizontal momentum conservation equation at any moment:

$\left(\mathbf{V}_{g}-\mathbf{C}\right) \cdot \nabla \mathbf{V}_{g}+f \mathbf{k} \times \mathbf{V}_{g}+\frac{1}{\rho} \nabla p=0$

where $\mathbf{k} \times \mathbf{V}_{g}$ denotes a vector, $\left(-V_{y}, V_{x}\right)^{\top}$. Therefore, the validity of a gradient wind field, $\mathbf{v}_{g}=\left(V_{x^{\prime}} V_{y}\right)^{\top}$, can be measured by the residuals of the above equation, $\mathbf{E}=\left(E_{x^{\prime}} E_{y}\right)^{\top}$, as defined below: 
$E_{x}=\left(V_{x}-c_{x}\right) \frac{\partial V_{x}}{\partial x}+\left(V_{y}-c_{y}\right) \frac{\partial V_{x}}{\partial y}-f V_{y}+\frac{1}{\rho} \frac{\partial p}{\partial x}$

$E_{y}=\left(V_{x}-c_{x}\right) \frac{\partial V_{y}}{\partial x}+\left(V_{y}-c_{y}\right) \frac{\partial V_{y}}{\partial y}+f V_{x}+\frac{1}{\rho} \frac{\partial p}{\partial y}$

We can readily evaluate the residuals without any spatial resolution errors, since the analytical forms for the gradient wind $\mathbf{V}_{g}=\left(V_{x}, V_{y}\right)^{\top}$ and all the spatial derivatives are available for each model as described in the previous section. The analytical forms for the pressure gradient terms are also easily derived using the chain rule shown below:

$\frac{\partial p}{\partial x}=\frac{\partial p}{\partial r} \frac{\partial r}{\partial x}=\frac{B \Delta p r_{m}^{B} X}{r^{B+2}} \exp \left(-\left(\frac{r_{m}}{r}\right)^{B}\right)$

$\frac{\partial p}{\partial y}=\frac{\partial p}{\partial r} \frac{\partial r}{\partial y}=\frac{B \Delta p r_{m}^{B} y}{r^{B+2}} \exp \left(-\left(\frac{r_{m}}{r}\right)^{B}\right)$

The residuals evaluated by the analytical forms were verified by those numerically evaluated using the 2 ndorder central finite difference scheme for spatial derivatives appearing in Eqs. (40a) and (40b).

\subsection{Evaluation results}

To allow a quantitative comparison among the three models, a set of computational conditions was specifically arranged as shown in Table 1, assuming a cyclone translating toward the north-west. The gradient wind fields and the residuals were computed using the analytical form for the gradient wind $\mathbf{V}_{g}=\left(V_{x^{\prime}}, V_{y}\right)^{\top}$ and the spatial derivatives at $1000 \times 1000$ points, regularly placed in a square domain. The center of the pressure distribution was assumed to be located at the center of the square domain at the moment of evaluation or $t=0$. Figure 4(a), (b) and (c) shows the contours of magnitude of the gradient wind,

Table 1 Conditions for gradient wind field computation

\begin{tabular}{ll}
\hline Width of square domain analyzed & $100 \mathrm{to} 1000 \mathrm{~km}$ \\
Number of evaluation points & $1000 \times 1000$ \\
Nominal radius to maximum wind speed, $r_{m}$ & $50 \mathrm{~km}$ \\
Pressure at the cyclone center, $p_{0}$ & $963 \mathrm{hPa}$ \\
Pressure far from the cyclone center, $p_{0}+\Delta p$ & $1013 \mathrm{hPa}$ \\
Cyclone translation speed in $x$-direction, $c_{x}$ & $-7.0 \mathrm{~m} / \mathrm{s}$ \\
Cyclone translation speed in $y$-direction, $c_{y}$ & $7.0 \mathrm{~m} / \mathrm{s}$ \\
Density of air, $\rho$ & $1.2 \mathrm{~kg} / \mathrm{m}^{3}$ \\
Latitude at the pressure center, $\varphi_{0}$ & $25 \mathrm{deg}$. \\
Sidereal rotation frequency of Earth, $\Omega$ & $0.7292107 \times 10^{-4} \mathrm{~s}^{-1}$ \\
B-value of Holland model, $B$ & 1.1 \\
\hline
\end{tabular}

\section{SN Applied Sciences}

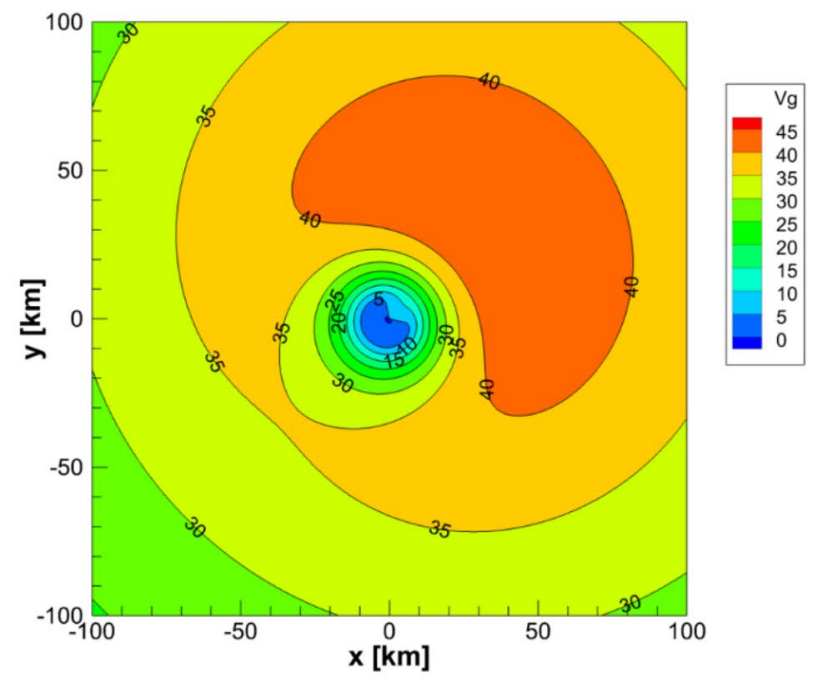

(a)
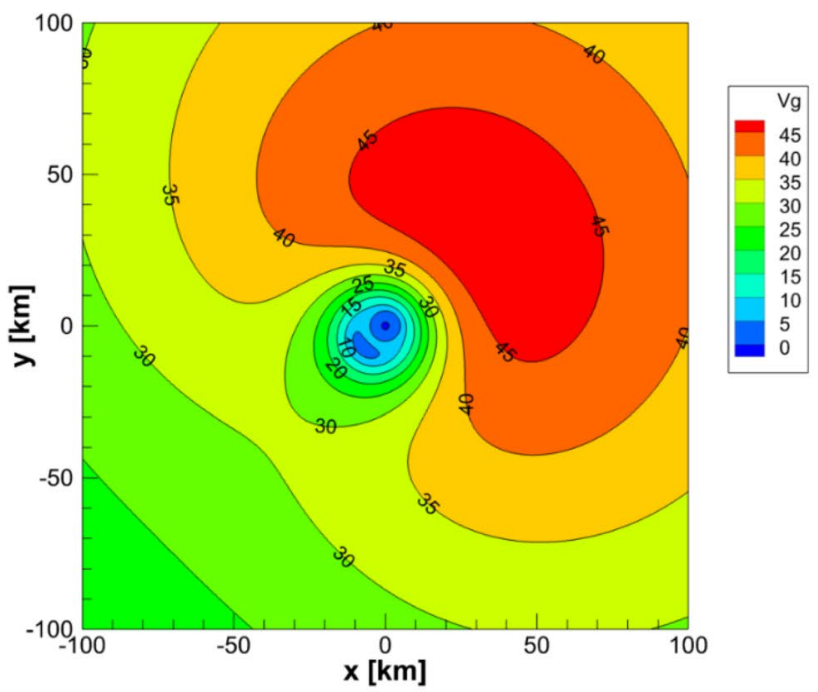

(b)

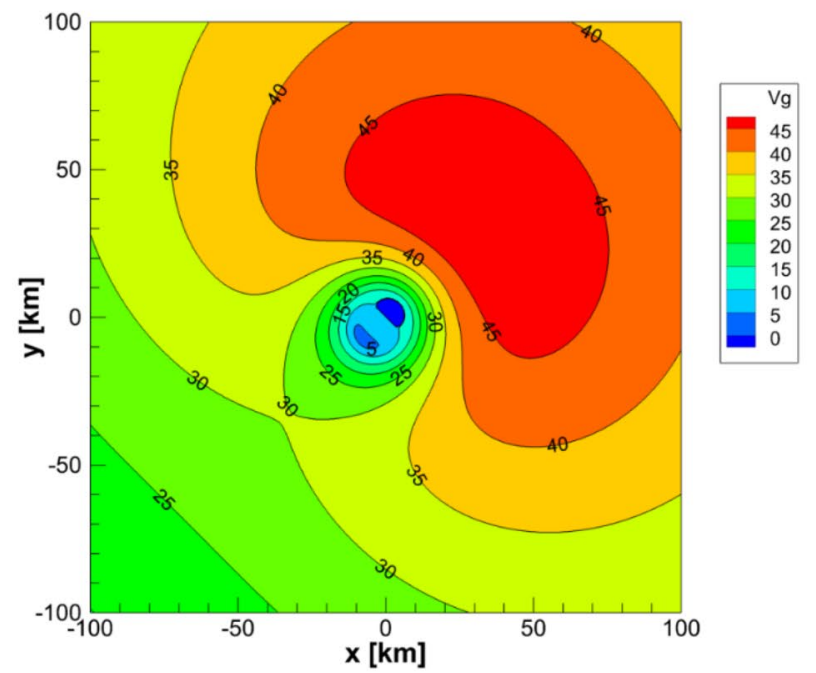

(c)

Fig. 4 Magnitude of the gradient wind [m/s]: a Georgiou's model, $\mathbf{b}$ Yoshizumi's model, and $\mathbf{c}$ Wang et al.'s model 
$V_{g^{\prime}}$ in a $200 \times 200 \mathrm{~km}$ square domain, obtained by Georgiou's model, Yoshizumi's model and Wang et al.'s model, respectively. The contour patterns of Yoshizumi's model and Wang et al.'s model are very similar, while those of Georgiou's model exhibit less severe wind speed in the region to the right of the translation direction.

To evaluate the degree of momentum conservation of the gradient wind models for the translating tropical cyclone, the residuals defined by Eqs. (40a) and (40b) were computed using the analytical forms in a $100 \times 100 \mathrm{~km}$ square domain. The magnitudes of the residuals, $|\mathbf{E}|$, are shown in Fig. 5(a), (b), and (c) with identical contour levels. These figures indicate that the residuals of Georgiou's model remained relatively large in the analyzed region, while those of Yoshizumi's model remained large only in a limited area near the pressure center. The residuals of Wang et al.'s model are invisible with the contour levels, though a real number solution for the gradient wind does not exist near the pressure center because of a negative value under the radical in Eq. (32). When no real number solution existed, zero values were allocated for $|\mathbf{E}|$ in Fig. 5(c) and $V_{g}$ in Fig. 4 (c) for plotting convenience. This allowed us to see the region of no solutions as the tilted D-shaped region near the origin in Fig. 5(c). The $L^{2}$-norm of the residuals, $E_{L}{ }^{2}$, defined below was computed using onepoint numerical integration for each of $1000 \times 1000$ square cells individually containing an evaluation point, which were regularly placed in a $200 \times 200 \mathrm{~km}$ square domain, $A$ :

$E_{L^{2}}=\sqrt{\int_{A}|\mathbf{E}|^{2} d S}=\sqrt{\int_{A}\left(E_{x}^{2}+E_{y}^{2}\right) d S}$

It should be noted that the numerical value of the $L^{2}-$ norm of the residuals, $E_{L}{ }^{2}$, num , should have some resolution error because the magnitude of the residual, $|\mathbf{E}|$, is assumed to be constant within each cell when a numerical integration is performed as below.

$E_{L^{2}, \text { num }}=\sqrt{\sum_{i=1}^{N}\left|\mathbf{E}_{i}\right|^{2} \Delta x \Delta y}=\sqrt{A} \sqrt{\frac{1}{N} \sum_{i=1}^{N}\left|\mathbf{E}_{i}\right|^{2}}$

where $N, \Delta x \Delta y$ and $A$, respectively, denote number of cells (or number of evaluation points), a cell area and a total area $(=N \Delta x \Delta y)$, while $\left|E_{i}\right|$ is magnitude of the residuals at the $i$-th cell. The main results obtained for the three models are summarized in Table 2. The maximum wind speed of Georgiou's model was the lowest among the three, while that of the other two models was almost the same. It is also seen that $L^{2}$-norm of the residuals was the largest (or the worst) with Georgiou's model, while Yoshizumi's model and Wang et al.'s model performed better.

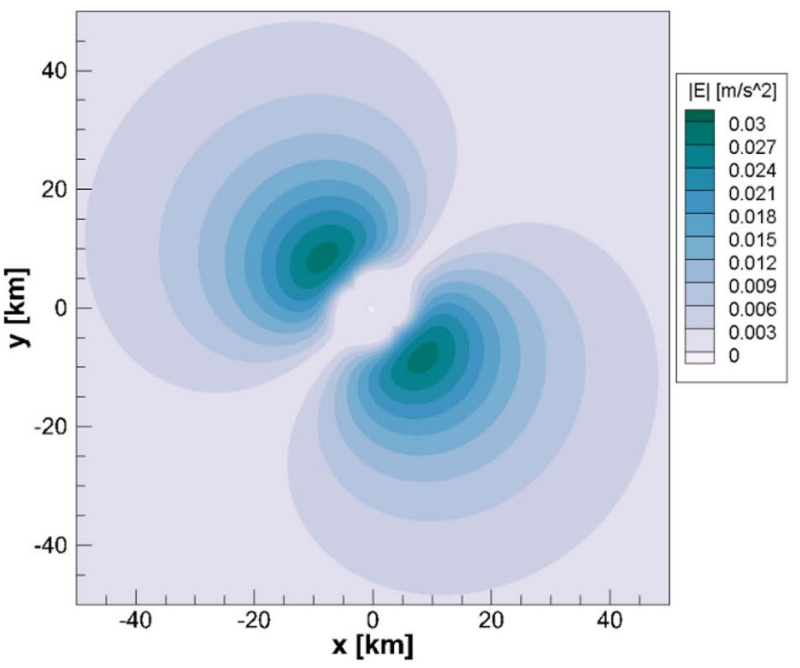

(a)

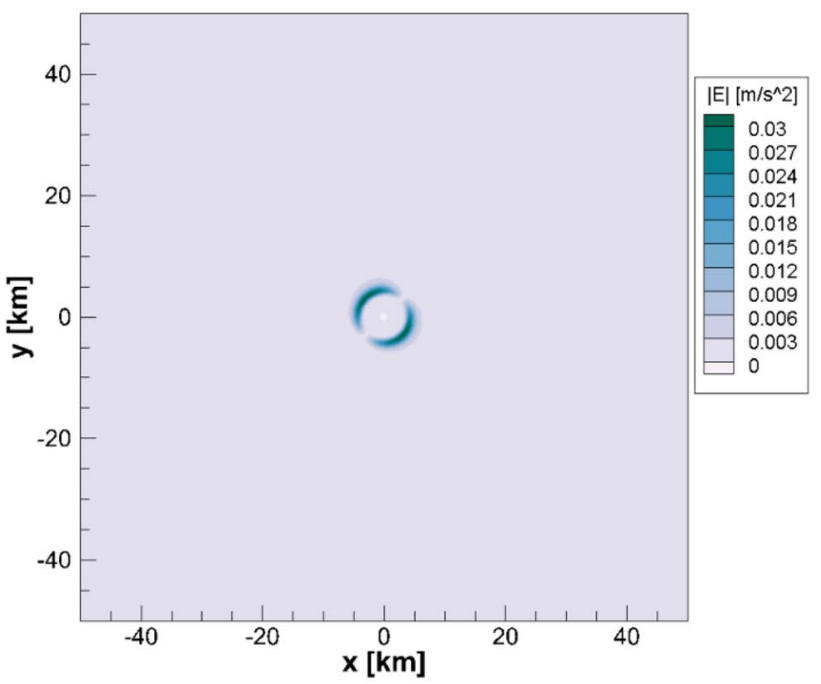

(b)

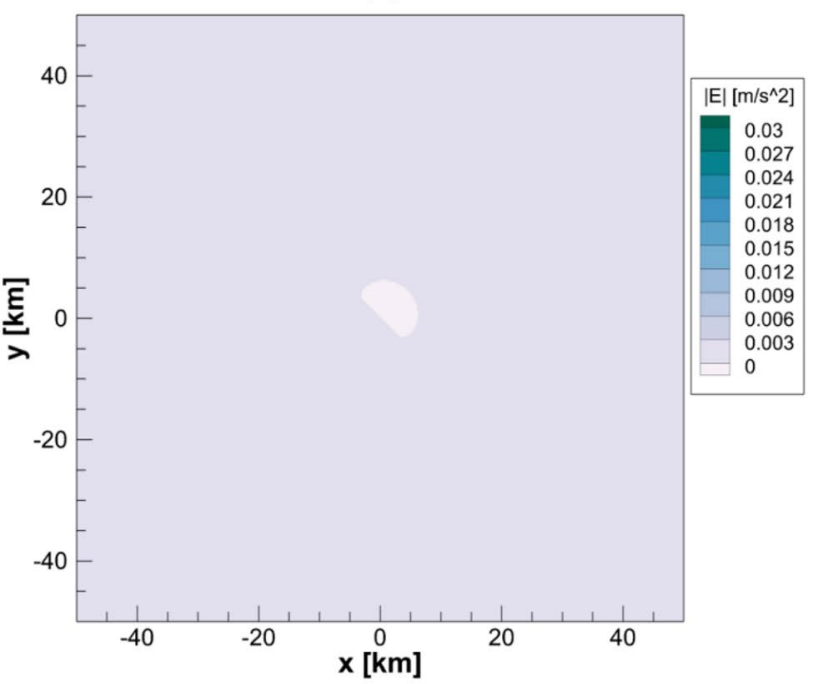

(c)

Fig. 5 Magnitude of the residuals in momentum conservation equations [m/ $\mathrm{s}^{2}$ ]: a Georgiou's model, b Yoshizumi's model, and c Wang et al.'s model 
Table 2 Main results for the gradient wind computed within a $200 \times 200 \mathrm{~km}$ square domain

\begin{tabular}{lll}
\hline Model & Maximum speed $[\mathrm{m} / \mathrm{s}]$ & $\begin{array}{l}L^{2} \text {-norm } \\
\text { of residual } \\
{\left[\mathrm{m}^{2} / \mathrm{s}^{2}\right]}\end{array}$ \\
\hline Georgiou & 44.7 & 786.2 \\
Yoshizumi & 48.8 & 152.7 \\
Wang et al. & 49.1 & 126.6 \\
\hline
\end{tabular}

\section{Validation using observation data}

Wang et al. [12] evaluated the accuracy of Georgiou's model and Wang et al's model by comparing the model results with observation data of sea surface wind speeds of Hurricanes Emily (19, July 2005) and Wilma (24, October 2005), archived in $\mathrm{H}^{*}$ WIND [20]. In their evaluation, the gradient wind speed of each model was adjusted to the surface wind speed simply by multiplying the model wind speed by a reduction factor so that the maximum wind speed of each model matched that of the observation data. On the basis of the surface wind speeds adjusted in this way, they claimed an overestimation of wind speed with Georgiou's model and good agreement with Wang et al.'s model, in comparison with the observed data.

In this section, the gradient wind speeds and directions of the three models were compared with the above observation data without any artificial matching. The radial profiles of wind speed are also compared for validation of the models. The RMSE (root-mean-square error) and MAE (mean-absolute-error) of wind speeds between each model and observation were computed for comparison and their correlations with the $L^{2}$-norm of the residuals are shown.

\subsection{Hurricane Emily, 2005}

The observation data for Hurricane Emily at 0929z, on 19 July 2005 were selected for validation of the models, as also selected by Wang et al. [12]. The data archived in $\mathrm{H}^{*}$ WIND [20] contain the maximum sustained 1-min wind (MS1W) velocity vectors at the height of $10 \mathrm{~m}$ above the sea surface on $161 \times 161$ grids as well as the minimum pressure at the hurricane center. Since the translation speed and direction are not explicitly described in $\mathrm{H}^{*}$ WIND, the translation speed was estimated from the positions of the hurricane center at 0730z, 0929z and $1030 z$. The translation direction at $0929 \mathrm{z}$ was determined so that the direction was perpendicular to the position vector of the observed maximum wind speed at 0929z. The nominal radius to maximum wind speed, $r_{m}$, was set at 1.07 times the radius to the observed maximum wind speed (RMW) because the computed RMWs shown in
Table 3 Computational conditions for Hurricane Emily, 2005

\begin{tabular}{ll}
\hline Area of rectangular domain analyzed & $884.07 \times 964.14 \mathrm{~km}$ \\
Number of evaluation points & $161 \times 161$ \\
Nominal radius to maximum wind speed, $r_{m}$ & $61.10 \mathrm{~km}$ \\
Pressure at the hurricane center, $p_{0}$ & $977 \mathrm{hPa}$ \\
Pressure far from the hurricane center, $p_{0}+\Delta p$ & $1013 \mathrm{hPa}$ \\
Hurricane translation speed in $x$-direction, $c_{x}$ & $-3.609 \mathrm{~m} / \mathrm{s}$ \\
Hurricane translation speed in $y$-direction, $c_{y}$ & $4.412 \mathrm{~m} / \mathrm{s}$ \\
Density of air, $\rho$ & $1.123 \mathrm{~kg} / \mathrm{m}^{3}$ \\
Latitude at the pressure center, $\varphi_{0}$ & $23.516 \mathrm{deg}$. \\
Sea surface temperature, $T_{s}$ & $303 \mathrm{~K}\left(30{ }^{\circ} \mathrm{C}\right)$ \\
B-value of Holland model, $B$ & 1.199 \\
\hline
\end{tabular}

Fig. 4(a) to (c) were less than the nominal radius to maximum wind speed, $r_{m}$, by approximately $7 \%$. Since the pressure distribution is not described in $\mathrm{H}^{*} \mathrm{WIND}$, we employed the statistical model for Holland's $B$ parameter proposed by Vickery and Wadhera [22] as shown below:

$$
B=1.7642-\frac{1.2098 \sqrt{R_{M W} f}}{\left\{2 R_{d}\left(T_{s}-273\right) \ln \left(1+\frac{\Delta p}{e p_{0}}\right)\right\}^{1 / 4}}
$$

where $R_{d} T_{s}$ and $e$ are the gas constant for dry air $[\mathrm{J} / \mathrm{kg} / \mathrm{K}]$, sea surface temperature $[\mathrm{K}]$ and the base of natural logarithms. $R_{M W}$ in Eq. (45) is the radius to the maximum wind speed expressed in meters. The computational conditions for Hurricane Emily, 2005 are summarized in Table 3.

Figure 6(a) shows the magnitude of the observed wind speed of Hurricane Emily, 2005 as the MS1W speed at $10 \mathrm{~m}$ above the sea surface, while Fig. 6(b), (c) and (d) shows the gradient wind speeds computed with Georgiou's model, Yoshizumi's model, and Wang et al's model, respectively. The wind direction angle of these wind fields, $D$, is shown by contours of conventional meteorological wind direction in degree and the wind velocity vector by arrows in Fig. 7(a) to (d) in the same order as Fig. 6(a) to (d). Figure 8 demonstrates the radial profile of the wind speeds extracted on a line from the south-west corner to the north-east corner through the pressure center of Fig. 6(a), (b), (c) and (d). Qualitatively good agreement between the observation data and the computed winds can be seen in Figs. 6 and 7, especially, near the pressure center. It is seen in Fig. 8 that two peak wind speeds of Yoshizumi's and Wang et al's models almost perfectly match those of the observations, although it should be noted that the gradient wind and MS1W are not directly commutable owing to the difference of the averaging period. In contrast, the profile of Georgiou's model exhibits quite inconsistent features because the first peak of Georgiou's model is lower than that of observation, while the second peak is higher. 


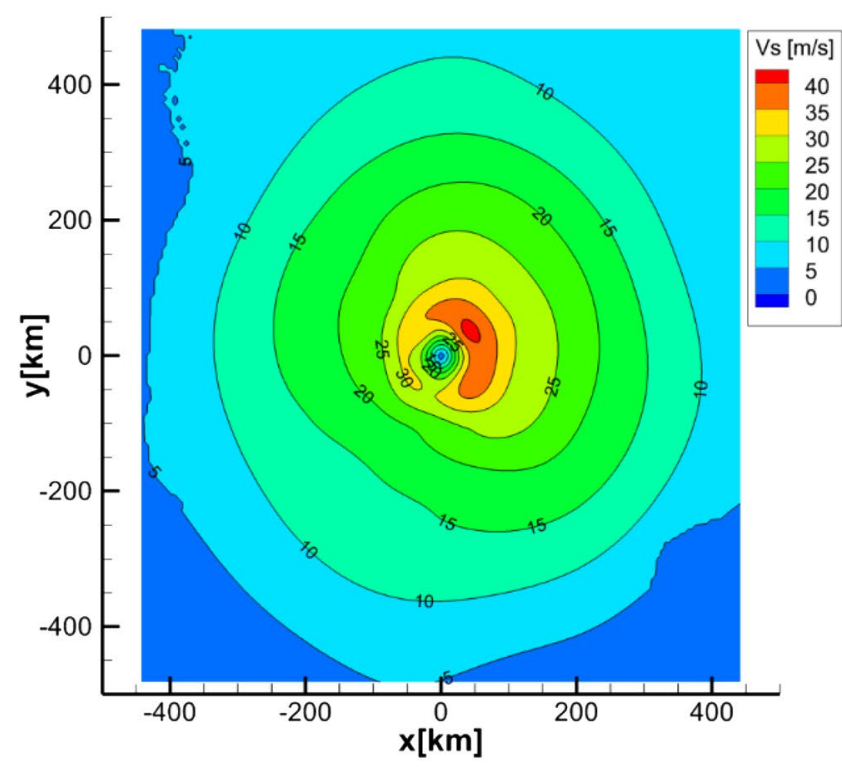

(a)

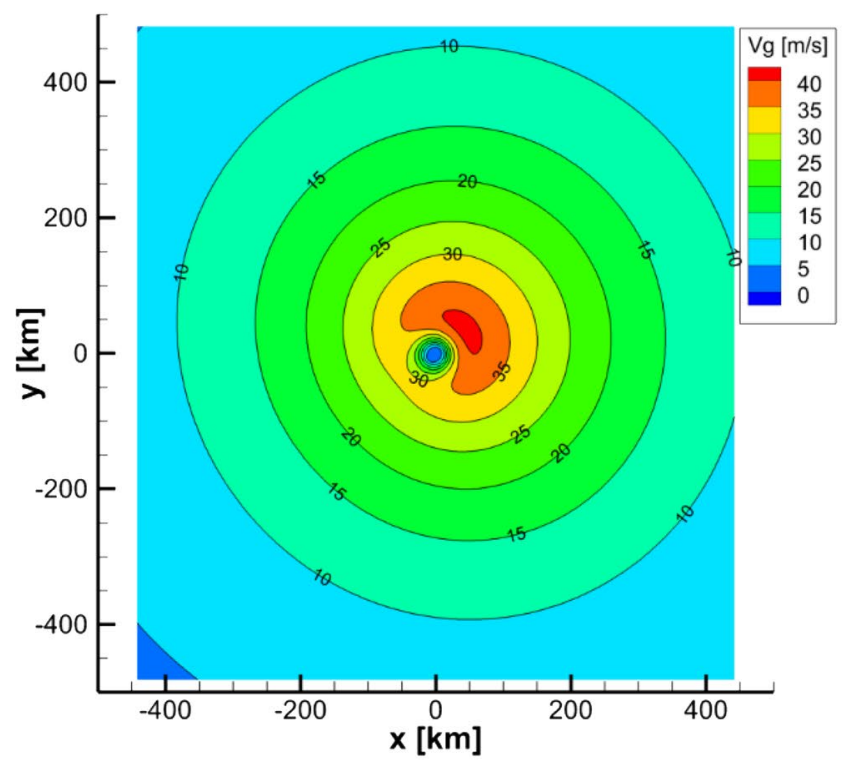

(c)

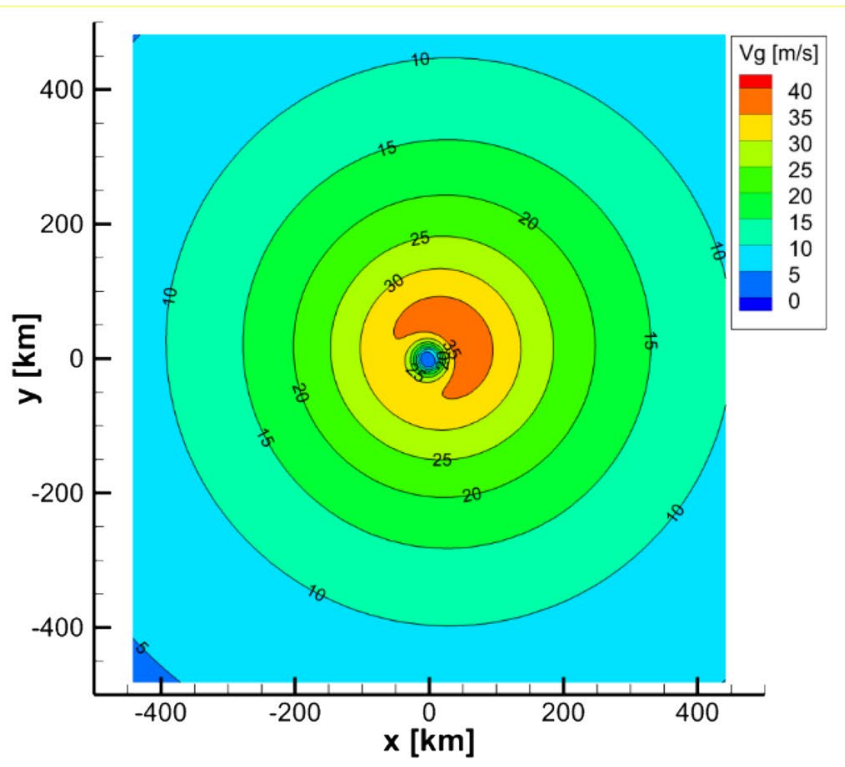

(b)

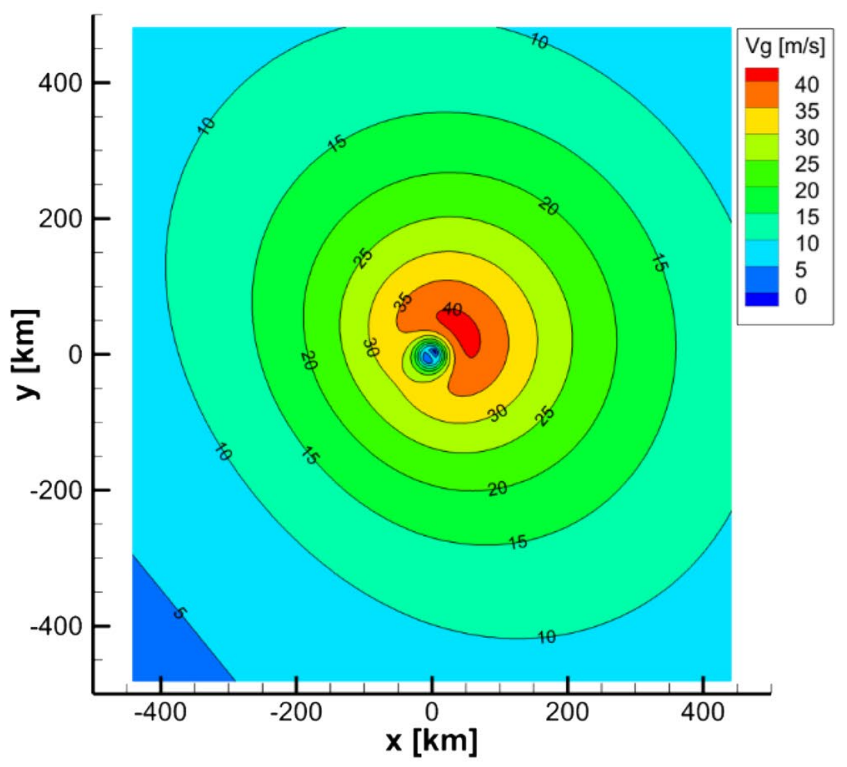

(d)

Fig. 6 Magnitude of the wind speed of Hurricane Emily, 2005 [m/s]: a MS1W speed near sea surface of observation, $\mathbf{b}$ gradient wind of Georgiou's model, c gradient wind of Yoshizumi's model, and $\mathbf{d}$ gradient wind of Wang et al.'s model

To quantitatively estimate the agreement, the following two error measures, RMSE and MAE, were calculated with variation in a reduction factor for gradient wind speed, $\beta(0<\beta<1)$.

$$
\operatorname{RMSE}(\beta)=\sqrt{\frac{1}{N} \sum_{i=1}^{N}\left(\beta V_{g, i}-V_{s, i}\right)^{2}}
$$

$\operatorname{MAE}(\beta)=\frac{1}{N} \sum_{i=1}^{N}\left|\beta V_{g, i}-V_{s, i}\right|$

where $N, V_{g, i}$ and $V_{s, i}$ are the number of evaluation grids, the gradient wind speed of each model at the $i$-th grid and the observed wind speed near sea surface at the $i$-th grid, respectively. The RMSRES (root of mean square of residuals), defined below, was also computed for the gradient wind fields of the three models. 


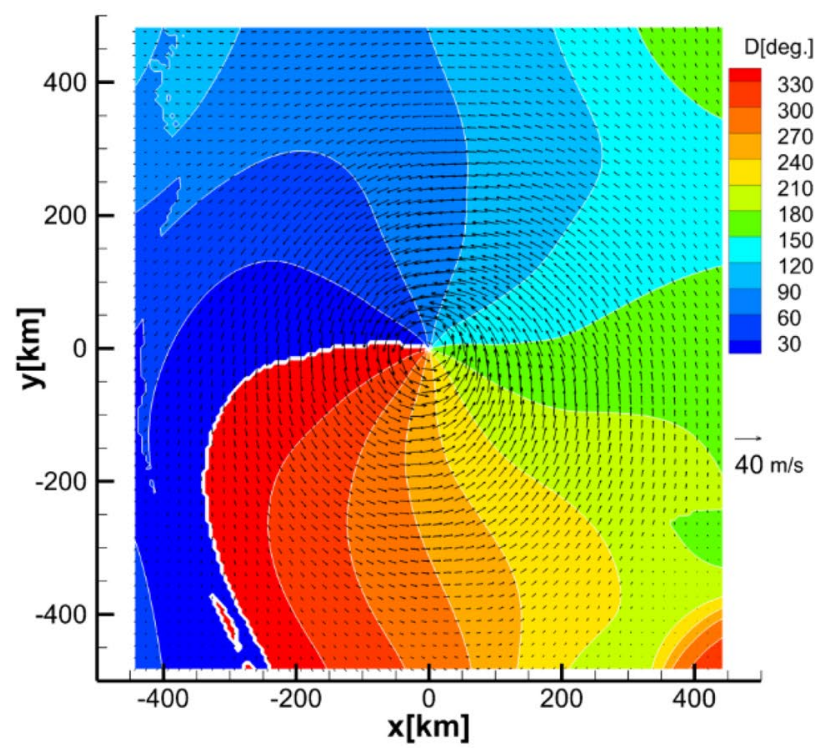

(a)

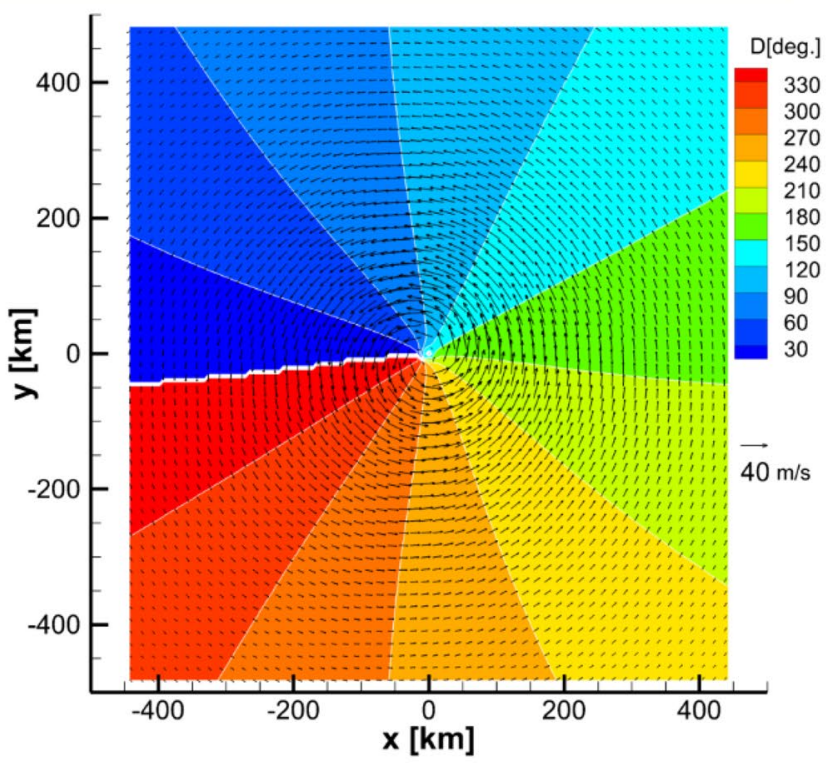

(c)

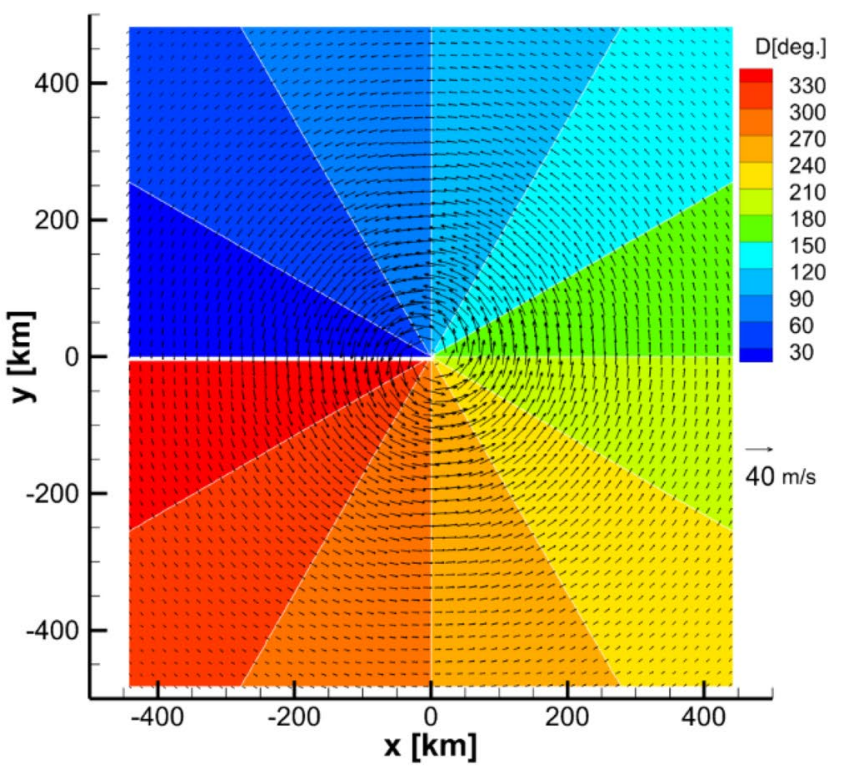

(b)

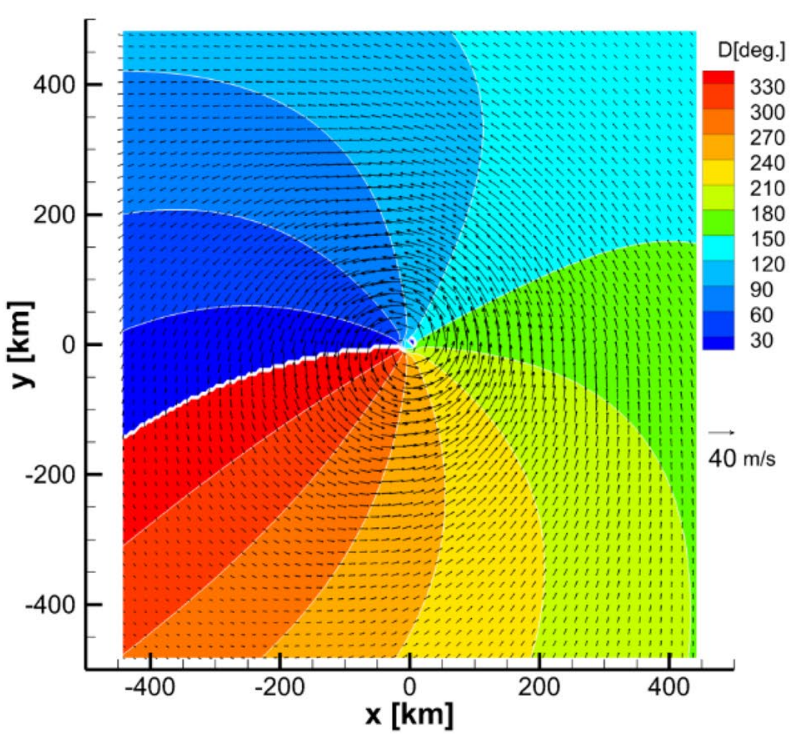

(d)

Fig. 7 Wind direction of Hurricane Emily, 2005 [deg.]: a MS1W near sea surface of observation, b gradient wind of Georgiou's model, c gradient wind of Yoshizumi's model, and $\mathbf{d}$ gradient wind of Wang et al.'s model

RMSRES $=\sqrt{\frac{1}{N} \sum_{i=1}^{N}\left|\mathbf{E}_{i}\right|^{2}}$

where $\mathbf{E}_{i}$ is the residual vector, $\left(E_{x}, E_{y}\right)^{\top}$, at the $i$-th grid. It is seen from Eq. (44) that the RMSRES defined above is equal to the $L^{2}$-norm of the residuals multiplied by the square of the evaluation area.
The evaluations of these error measures were performed for the whole region and for the near-center region $\left(r<2 r_{m}\right)$. Table 4 shows the minimum values of the RMSE along with the RMSRES for each model, while Table 5 shows the minimum values of the MAE. It can be found from the tables that Georgiou's model had the largest RMSE, MAE and RMSRES among the three models, 


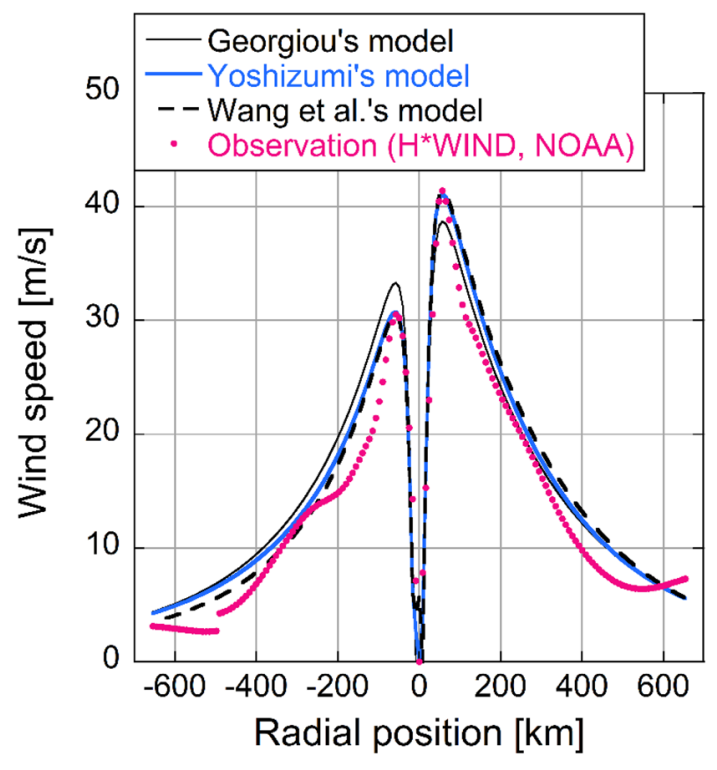

Fig. 8 Radial profile of wind speed from the south-west corner to the north-east corner of the analyzed domain for Hurricane Emily, 2005

suggesting the wind field computed with Georgiou's model deviates most from observational and theoretical wind fields. Clear correlation of the RMSE, MAE and the $L^{2}$-norm of residuals can be seen for the case of the nearcenter region $\left(r<2 r_{m}\right)$ in Fig. 9, where the RMSE and MAE normalized by the values of Georgiou's model are plotted against the normalized $L^{2}$-norm of residuals (or the normalized RMSRES).

\subsection{Hurricane Wilma, 2005}

The observation data for Hurricane Wilma at 0730z, on 24 October 2005 were selected for validation of the models, as also selected by Wang et al. [12]. The computational conditions were set up in the same way as the previous subsection, and are summarized in Table 6 .

Figure 10(a) shows the magnitude of the MS1W speed at $10 \mathrm{~m}$ above the sea surface observed for Hurricane Wilma, 2005, while Fig. 10(b), (c) and (d) shows the gradient wind speeds computed with Georgiou's model, Yoshizumi's model, and Wang et al.'s model, respectively. The wind direction of these wind fields is shown by contours
Table 5 MAE for Hurricane Emily, 2005

\begin{tabular}{llllll}
\hline model & \multicolumn{2}{l}{ Whole region } & & \multicolumn{2}{l}{ Near center $\left(r<2 r_{m}\right)$} \\
\cline { 2 - 3 } \cline { 5 - 6 } & $\beta_{\min }$ & $\operatorname{MAE}\left(\beta_{\min }\right)[\mathrm{m} / \mathrm{s}]$ & & $\beta_{\min }$ & $\operatorname{MAE}\left(\beta_{\min }\right)[\mathrm{m} / \mathrm{s}]$ \\
\hline Georgiou & 0.884 & 1.521 & 0.915 & 2.288 \\
Yoshizumi & 0.888 & 1.310 & 0.895 & 1.829 \\
Wang et al. & 0.861 & 1.493 & 0.891 & 1.806 \\
\hline
\end{tabular}

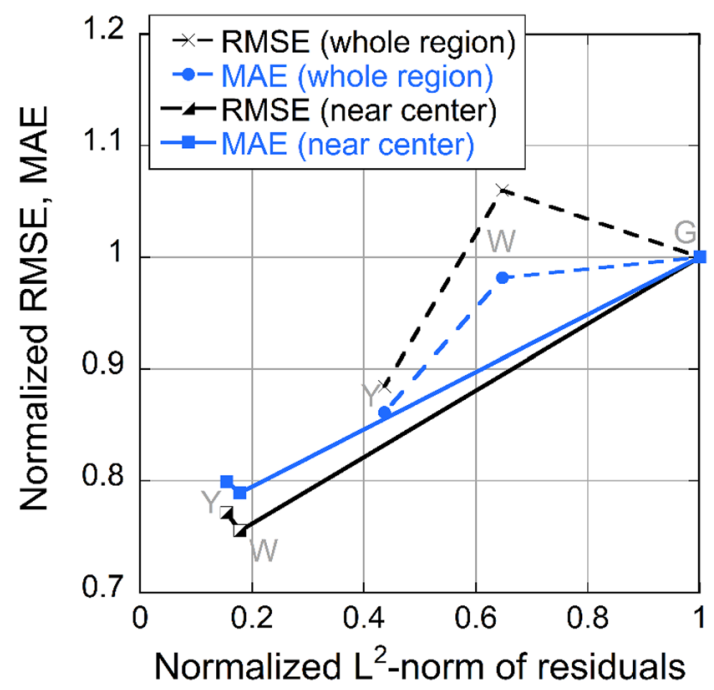

Fig. 9 Normalized RMSE and MAE against normalized $L^{2}$-norm of residuals for Hurricane Emily, 2005

of conventional meteorological wind direction in degree and by arrows of the wind velocity vectors in Fig. 11(a) to (d) in the same order as Fig. 10(a) to (d). Figure 12 demonstrates the radial profile of the wind speeds extracted on a line from the north-west corner to the south-east corner through the pressure center of Fig. 10(a), (b), (c) and (d). Qualitative agreement between the observation data and the computed winds can be seen in Figs. 10 and 11, especially near the pressure center. It is seen in Fig. 12 that the highest peak wind speeds of Yoshizumi's and Wang et al.'s models match well with that of the observation, though the averaging period of gradient wind is considered to be much longer than that of MS1W (i.e., 1 min). However, the highest peak wind speed of Georgiou's model is lower than that of the observation, while the wind speed at the second peak is higher than those of the observation and
Table 4 RMSE and RMSRES for Hurricane Emily, 2005

\begin{tabular}{|c|c|c|c|c|c|c|}
\hline \multirow[t]{2}{*}{ model } & \multicolumn{3}{|c|}{ Whole region } & \multicolumn{3}{|c|}{ Near center $\left(r<2 r_{m}\right)$} \\
\hline & $\beta_{\min }$ & $\operatorname{RMSE}\left(\beta_{\min }\right)[\mathrm{m} / \mathrm{s}]$ & $\operatorname{RMSRES}\left[\mathrm{m} / \mathrm{s}^{2}\right]$ & $\beta_{\text {min }}$ & $\operatorname{RMSE}\left(\beta_{\min }\right)[\mathrm{m} / \mathrm{s}]$ & RMSRES $\left[\mathrm{m} / \mathrm{s}^{2}\right]$ \\
\hline Georgiou & 0.880 & 1.917 & $4.65 \times 10^{-4}$ & 0.906 & 2.892 & $1.92 \times 10^{-3}$ \\
\hline Yoshizumi & 0.876 & 1.696 & $2.03 \times 10^{-4}$ & 0.900 & 2.231 & $2.97 \times 10^{-4}$ \\
\hline Wang et al. & 0.851 & 2.032 & $3.01 \times 10^{-4}$ & 0.898 & 2.184 & $3.43 \times 10^{-4}$ \\
\hline
\end{tabular}


Table 6 Computational conditions for Hurricane Wilma, 2005

$\begin{array}{ll}\text { Area of rectangular domain analyzed } & 872.30 \times 964.26 \mathrm{~km} \\ \text { Number of evaluation points } & 161 \times 161 \\ \text { Nominal radius to maximum wind speed, } r_{m} & 77.87 \mathrm{~km} \\ \text { Pressure at hurricane center, } p_{0} & 952 \mathrm{hPa} \\ \text { Pressure far from the hurricane center, } p_{0}+\Delta p & 1013 \mathrm{hPa} \\ \text { Hurricane translation speed in } x \text {-direction, } c_{x} & 5.569 \mathrm{~m} / \mathrm{s} \\ \text { Hurricane translation speed in } y \text {-direction, } c_{y} & 6.297 \mathrm{~m} / \mathrm{s} \\ \text { Density of air, } \rho & 1.094 \mathrm{~kg} / \mathrm{m}^{3} \\ \text { Latitude at the pressure center, } \varphi_{0} & 25.859 \mathrm{deg} . \\ \text { Sea surface temperature, } T_{s} & 303 \mathrm{~K}\left(30^{\circ} \mathrm{C}\right) \\ \text { B-value of Holland model, } B & 1.189\end{array}$

the other two models. According to the validation results of Hurricanes Emily and Wilma, it is possible to assert that the difference of wind speeds at the first and the second peaks of Georgiou's model is too small to be consistent with the observations.

To quantitatively estimate the agreement, the RMSE, MAE and RMSRES were computed for the whole region and for the near-center region $\left(r<2 r_{m}\right)$. Table 7 shows the minimum values of RMSE along with RMSRES for each model, while Table 8 shows the minimum values of MAE. It can be found from the tables that Georgiou's model had the largest RMSE, MAE and RMSRES among the three models, except for the RMSE of Wang et al.'s model for the whole region. The relationships of normalized values of RMSE, MAE and the $L^{2}$-norm of residuals are shown in Fig. 13, where a clear correlation can be seen for the case of the near-center region $\left(r<2 r_{m}\right)$.

\section{Discussion}

\subsection{Characteristics of wind speed in each model}

The results shown in the previous sections indicate that the maximum wind speed of the Georgiou's model is less than those of the other two models and the MS1W speed near sea surface of observation. To see the difference of the wind speed characteristics over the large area among the three models, the gradient wind speed was computed within a $1000 \times 1000 \mathrm{~km}$ square domain using the conditions of Table 1. Then, the wind speed values computed at $1000 \times 1000$ points were sorted by magnitude to assess the relative frequency distributions. Figure 14 demonstrates the distributions of gradient wind speed in terms of the exceedance ratio, which represents the ratio of the number of grid points of wind speed beyond a value specified by abscissa. Figure 14 shows that the exceedance ratios decrease exponentially up to approximately $30 \mathrm{~m} / \mathrm{s}$ in all the models, and rapidly approach zero near the maximum speed of each model. It is also seen that the exceedance ratio curves of Yoshizumi's model and Wang et al.'s model are very close, especially in the high wind speed range, while that of Georgiou's model deviates from the curves of the other models above approximately $30 \mathrm{~m} / \mathrm{s}$. This means that Georgiou's model tends to underestimate wind speed in the high wind speed range in comparison with the other two models.

The residuals were also examined over the $1000 \times 1000 \mathrm{~km}$ area, which revealed that Georgiou's model is more accurate in terms of residual than the other two models in the region farther than about $80 \mathrm{~km}$ from the pressure center. This is consistent with the difference in the $L^{2}$-norms of residuals for the larger region $(1000 \times 1000 \mathrm{~km}$ square domain) and for the near-center region $(200 \times 200 \mathrm{~km}$ square domain) shown in Subsection 5.3. These residual characteristics suggest that Georgiou's model may perform best away from the pressure center.

\subsection{Curvature radii of streamlines and path lines}

As explained in Subsection 2.1, Georgiou [14] assumed that the curvature radius of the streamline was the same as that of the isobar line when computing the radius of curvature of the path line using Blaton's formula. To observe the difference in the curvature features of the three models, the radius of curvature of streamlines and the radius of curvature of path lines were computed using curvature formulae for the unsteady $2 \mathrm{D}$ vector field derived by Theisel [28]. According to the formulae, the radius of curvature of streamlines, $R_{S}$, can be computed as shown below for the vector field $\mathbf{V}_{g}=\left(V_{x}, V_{y}\right)^{\top}$ :

$R_{S}=\frac{\left|\mathbf{V}_{g}\right|^{3}}{\operatorname{det}\left[\mathbf{V}_{g^{\prime}} \mathbf{A}_{S}\right]}$

where acceleration, $\mathbf{A}_{s}$, is given as below and "det $\left[\mathbf{V}_{g^{\prime}} \mathbf{A}_{S}\right]$ " denotes determinant of matrix $\left[\mathbf{V}_{g}, \mathbf{A}_{s}\right]$ :

$\mathbf{A}_{S}=V_{x}\left(\begin{array}{c}\frac{\partial V_{x}}{\partial x} \\ \frac{\partial V_{y}}{\partial x}\end{array}\right)+V_{y}\left(\begin{array}{c}\frac{\partial V_{x}}{\partial y} \\ \frac{\partial V_{y}}{\partial y}\end{array}\right)$

Theisel [28] also showed a formula for the radius of curvature of path lines, $R_{p}$, for the vector field $\mathbf{v}_{g}=\left(V_{x^{\prime}}\right.$ $\left.V_{y}\right)^{\top}$, as follows: 


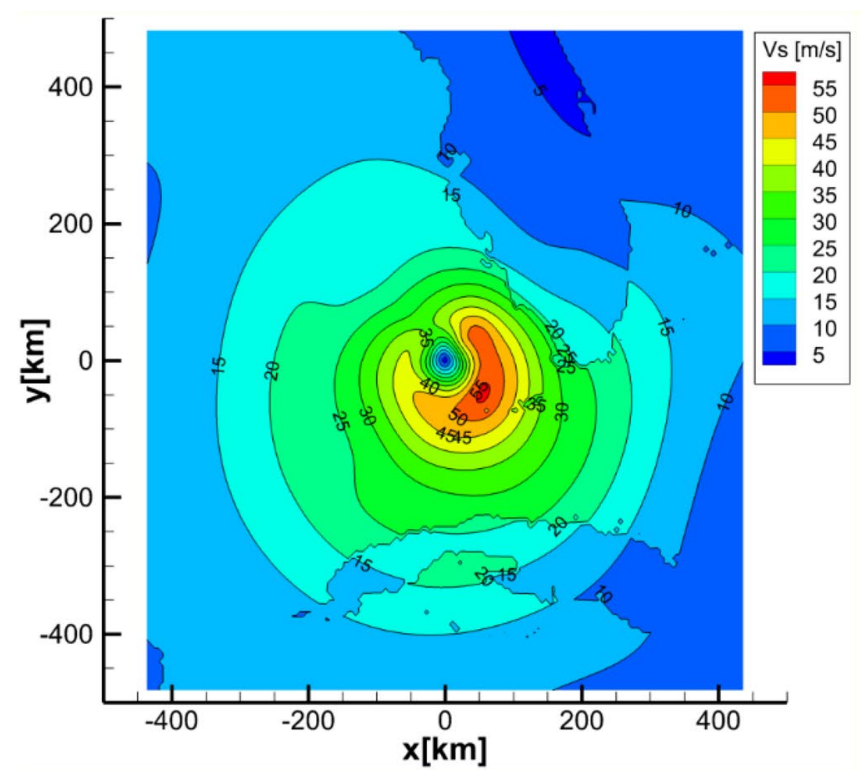

(a)

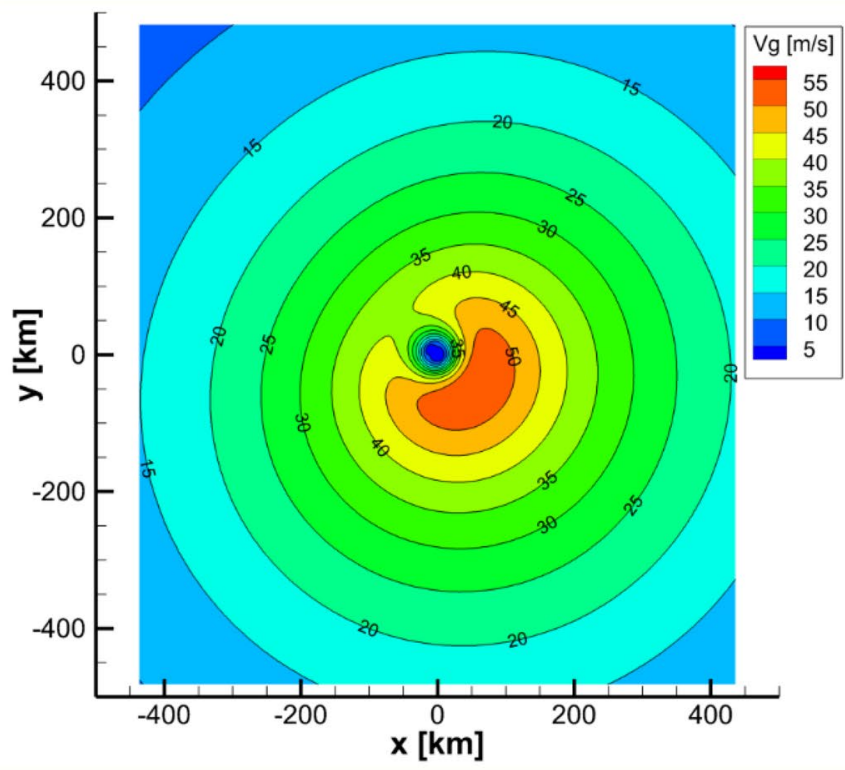

(c)

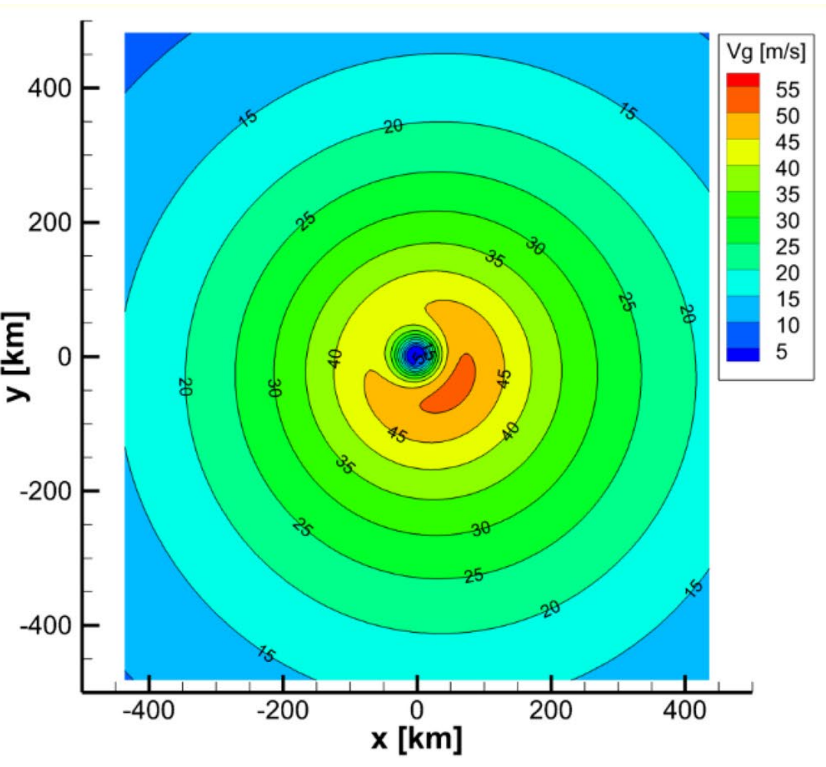

(b)

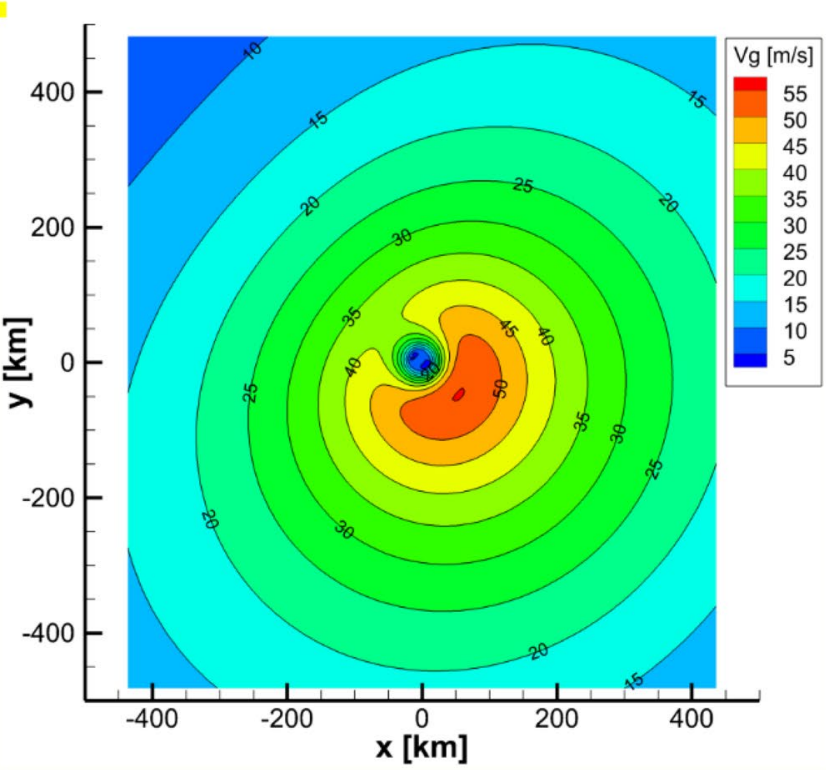

(d)

Fig. 10 Magnitude of the wind speed of Hurricane Wilma, 2005 [m/s]: a MS1W (maximum sustained 1-min wind) speed near sea surface of observation, b gradient wind of Georgiou's model, c gradient wind of Yoshizumi's model, and d gradient wind of Wang et al.'s model

$R_{P}=\frac{\left|\mathbf{V}_{g}\right|^{3}}{\operatorname{det}\left[\mathbf{V}_{g}, \mathbf{A}_{p}\right]}$

where acceleration, $\mathbf{A}_{p}$, is given as shown below and the denominator denotes the determinant of matrix $\left[\mathbf{V}_{g}, \mathbf{A}_{p}\right]$ :

$$
\mathbf{A}_{P}=V_{x}\left(\begin{array}{l}
\frac{\partial V_{x}}{\partial x} \\
\frac{\partial V_{y}}{\partial x}
\end{array}\right)+V_{y}\left(\begin{array}{l}
\frac{\partial V_{x}}{\partial y} \\
\frac{\partial V_{y}}{\partial y}
\end{array}\right)+\left(\begin{array}{l}
\frac{\partial V_{x}}{\partial t} \\
\frac{\partial V_{y}}{\partial t}
\end{array}\right)=\mathbf{A}_{S}+\left(\begin{array}{l}
\frac{\partial V_{x}}{\partial t} \\
\frac{\partial V_{y}}{\partial t}
\end{array}\right)
$$

The temporal derivatives appearing at the last term in Eq. (52) are computed using the following relationship, 


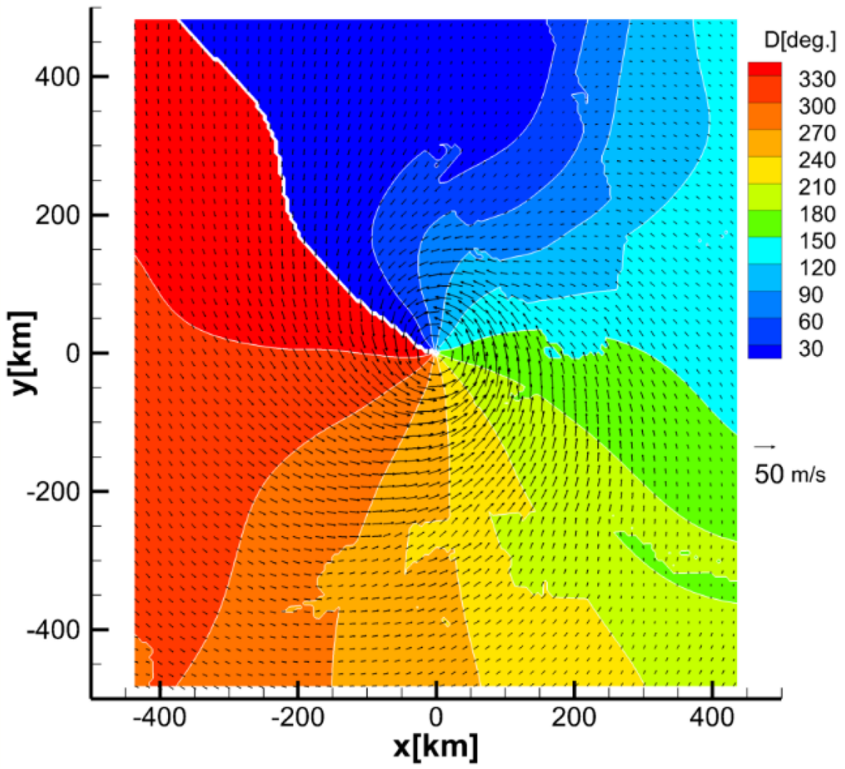

(a)

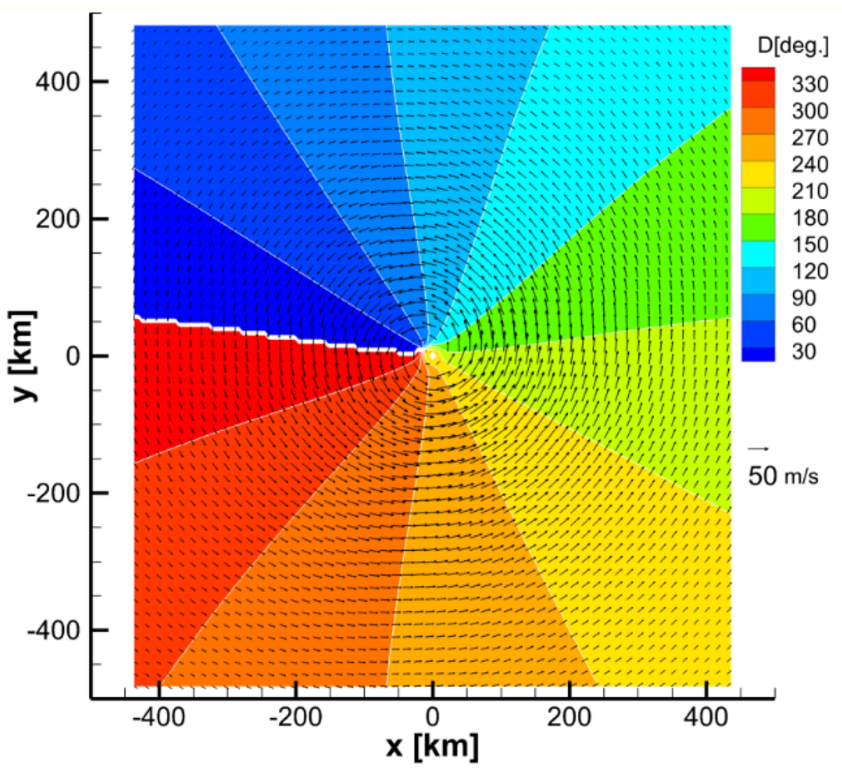

(c)

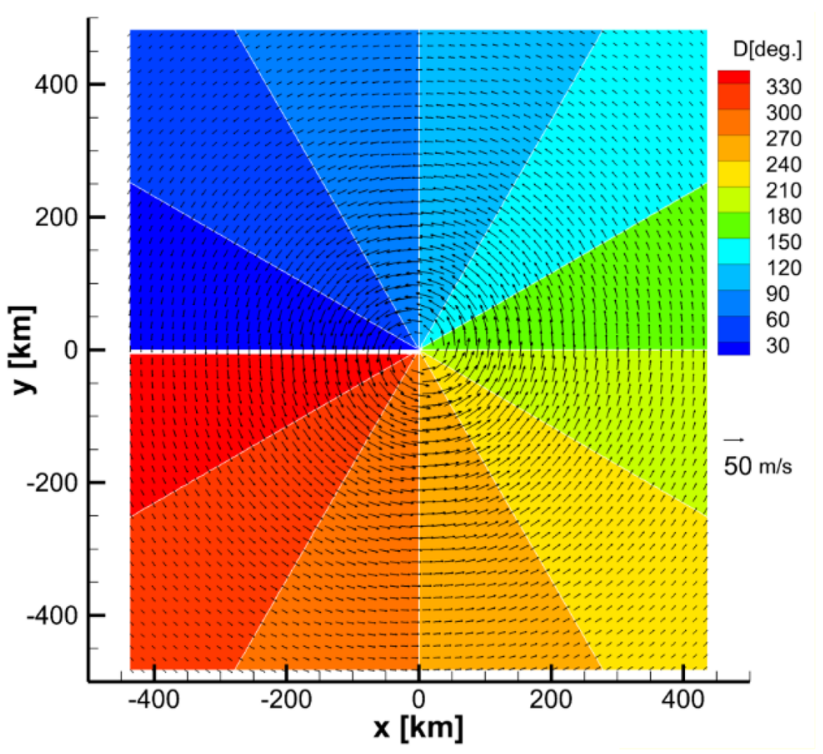

(b)

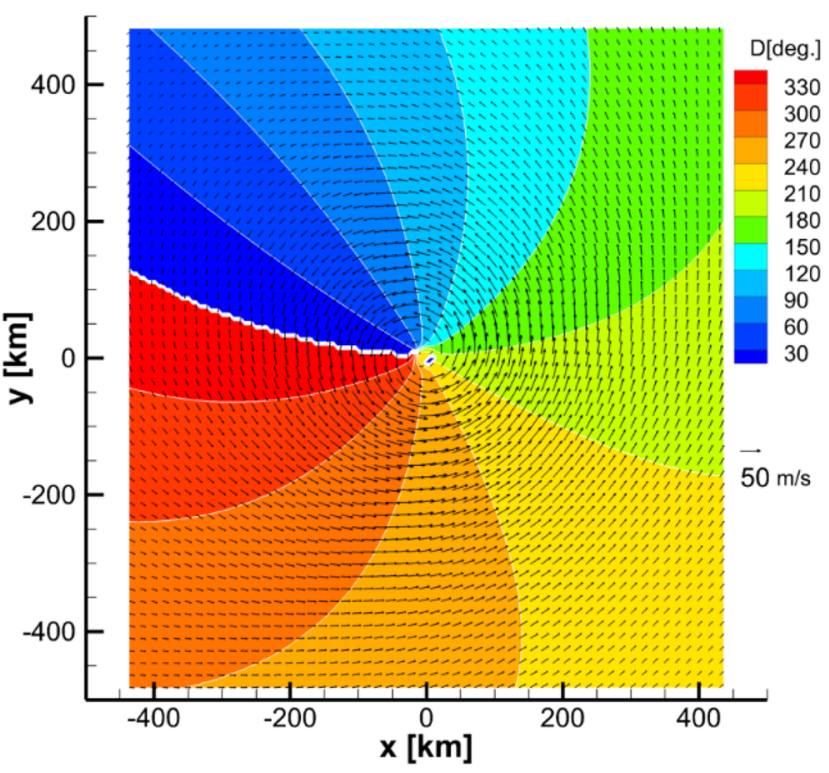

(d)

Fig. 11 Wind direction of Hurricane Wilma, 2005 [deg.]: a MS1W near sea surface of observation, b gradient wind of Georgiou's model, c gradient wind of Yoshizumi's model, and $\mathbf{d}$ gradient wind of Wang et al's model

which implies pure advection of the velocity field $\mathbf{V}_{g}$ with a constant translation vector, $\mathbf{C}=\left(c_{x}, c_{y}\right)^{\top}$ :

$\left(\begin{array}{l}\frac{\partial V_{x}}{\partial t} \\ \frac{\partial V_{y}}{\partial t}\end{array}\right)=-C_{x}\left(\frac{\frac{\partial V_{x}}{\partial x_{y}}}{\frac{\partial V_{y}}{\partial x}}\right)-c_{y}\left(\begin{array}{l}\frac{\partial V_{x}}{\partial V_{y}} \\ \frac{\partial V_{y}}{\partial y}\end{array}\right)$
Figure 15 shows the isolines of curvature radii of streamlines, $R_{S}$, at the contour levels of $50 \mathrm{~km}$ and $100 \mathrm{~km}$ for the three models. The isolines of Georgiou's model are concentric, perfectly coinciding with the isobar lines (circles) as assumed. However, the shapes of isolines for Yoshizumi's model and Wang et al.'s model are oval with larger radii of curvature to the right and smaller radii of curvature to the left of the translation direction than those of Georgiou's 


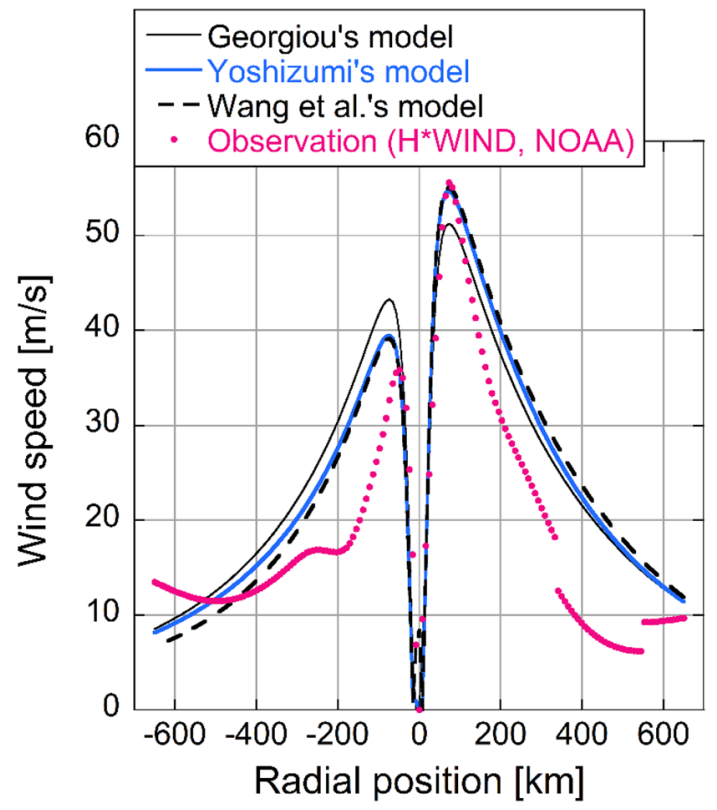

Fig. 12 Radial profile of wind speed from the north-west corner to the south-east corner of the analyzed domain for Hurricane Wilma, 2005

model (or the isobar line). Figure 16 shows the isolines of curvature radii of path lines, $R_{p}$, at the same levels for the three models. The isolines of Georgiou's model are almost concentric, though the isolines have moved to the left of the translation direction in comparison with the shape of isolines of curvature radii of streamlines, $R_{S}$, depicted in Fig. 15. In the region to the right of the translation direction, it is noted that the curvature radii of path line of Yoshizumi's model and Wang et al.'s model are larger than those of Georgiou's model. The difference in the curvature radius of path line explains the larger values of the maximum gradient wind in Yoshizumi's model and Wang et al.'s model, compared with Georgiou's model. This is because the gradient wind speed should increase so that the centrifugal force with large radius of curvature can balance the given pressure gradient force and the Coriolis force.

\subsection{Sensitivity to translation speed}

In the computations in Sect. 3, the translation speed, $|\mathbf{C}|$, was fixed at approximately $9.9 \mathrm{~m} / \mathrm{s}$ with $\mathbf{C}=(-7 \mathrm{~m} / \mathrm{s}$,
Table 8 MAE for Hurricane Wilma, 2005

\begin{tabular}{lllll}
\hline model & \multicolumn{2}{l}{ Whole region } & \multicolumn{2}{l}{ Near center $\left(r<2 r_{m}\right)$} \\
\cline { 2 - 4 } \cline { 3 - 4 } & $\beta_{\text {min }}$ & $\operatorname{MAE}\left(\beta_{\text {min }}\right)[\mathrm{m} / \mathrm{s}]$ & $\beta_{\text {min }}$ & $\begin{array}{l}\operatorname{MAE}\left(\beta_{\text {min }}\right) \\
{[\mathrm{m} / \mathrm{s}]}\end{array}$ \\
\hline Georgiou & 0.710 & 3.391 & 0.860 & 5.353 \\
Yoshizumi & 0.722 & 3.477 & 0.845 & 4.436 \\
Wang et al. & 0.693 & 3.844 & 0.840 & 4.347 \\
\hline
\end{tabular}

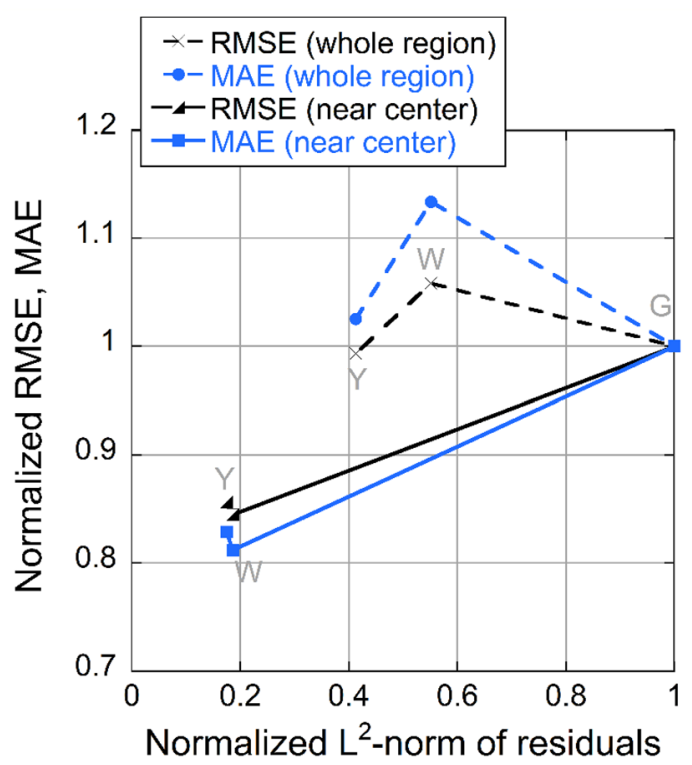

Fig. 13 Normalized RMSE and MAE against normalized $L^{2}$-norm of residuals for Hurricane Wilma, 2005

$7 \mathrm{~m} / \mathrm{s})$. In this subsection, we identify the impact of the translation speed on the maximum gradient wind speed, as well as the $L^{2}$-norm of the residuals, keeping the other conditions identical to those in Table 1. Figure 17 shows the maximum gradient wind speed with variation in the translation speed. The maximum gradient wind speeds of the three models coincide at zero translation speed. However, the deviations increase almost in proportion to the translation speed, becoming more prominent for a larger translation speed, for example, exceeding $10 \%$ above $10 \mathrm{~m} / \mathrm{s}$ of translation speed in the present case.

Figure 18(a) and (b) shows the $L^{2}$-norm of the residuals with variation in the translation speed integrated over a $200 \times 200 \mathrm{~km}$ square domain and a $1000 \times 1000 \mathrm{~km}$
Table 7 RMSE and RMSRES for Hurricane Wilma, 2005

\begin{tabular}{llllllll}
\hline model & \multicolumn{2}{l}{ Whole region } & & \multicolumn{3}{l}{ Near center $\left(r<2 r_{m}\right)$} \\
\cline { 2 - 3 } & $\beta_{\text {min }}$ & $\operatorname{RMSE}\left(\beta_{\min }\right)[\mathrm{m} / \mathrm{s}]$ & RMSRES $\left[\mathrm{m} / \mathrm{s}^{2}\right]$ & & $\beta_{\text {min }}$ & $\operatorname{RMSE}\left(\beta_{\min }\right)[\mathrm{m} / \mathrm{s}]$ & $\mathrm{RMSRES}\left[\mathrm{m} / \mathrm{s}^{2}\right]$ \\
\hline Georgiou & 0.699 & 4.627 & $8.94 \times 10^{-4}$ & & 0.851 & 6.365 & $2.90 \times 10^{-3}$ \\
Yoshizumi & 0.693 & 4.596 & $3.69 \times 10^{-4}$ & & 0.846 & 5.452 & $5.07 \times 10^{-4}$ \\
Wang et al. & 0.675 & 4.896 & $4.93 \times 10^{-4}$ & & 0.844 & 5.377 & $5.40 \times 10^{-4}$ \\
\hline
\end{tabular}




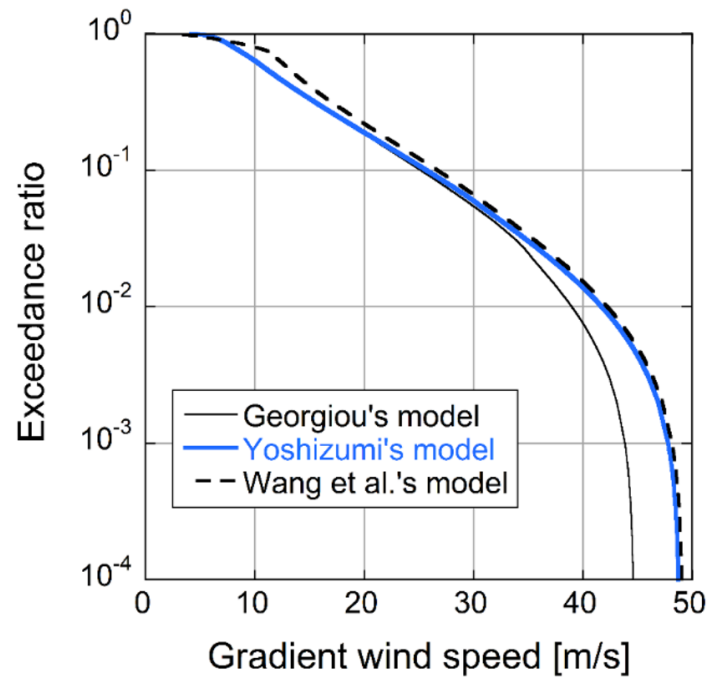

Fig. 14 Exceedance ratio of gradient wind speed within a $1000 \times 1000 \mathrm{~km}$ square domain

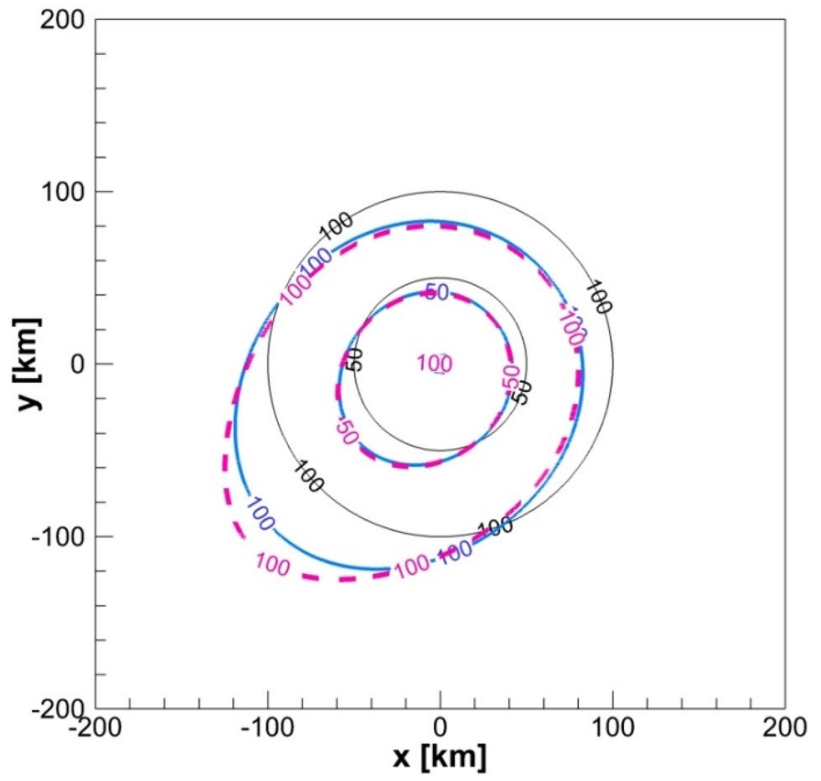

Fig. 15 Isolines of curvature radii [km] of streamlines: the thin solid lines represent Georgiou's model, the thick solid lines represent Yoshizumi's model, and the dashed lines represent Wang et al.'s model

square domain, respectively. The $L^{2}$-norms of the residuals vanish at zero translation speed for all the models. The $L^{2}$-norms of Yoshizumi's model and Wang et al.'s model are less than those of Georgiou's model, with both the integration domains. Wang et al.'s model performs best at the $200 \times 200 \mathrm{~km}$ square domain, while

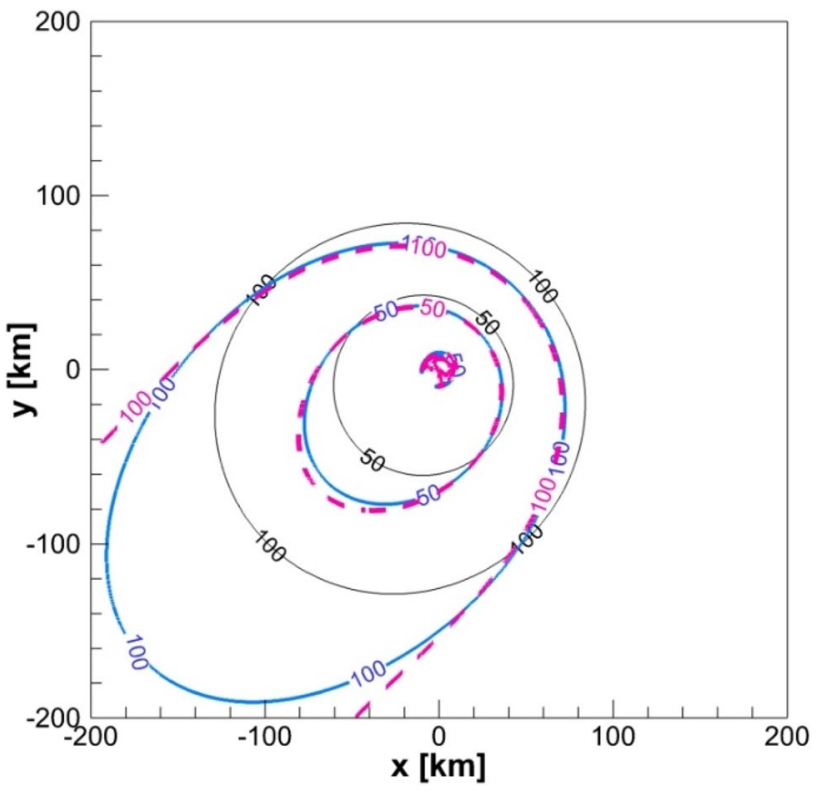

Fig. 16 Isolines of curvature radii [km] of path lines: the thin solid lines represent Georgiou's model, the thick solid lines represent Yoshizumi's model, and the dashed lines represent Wang et al's model

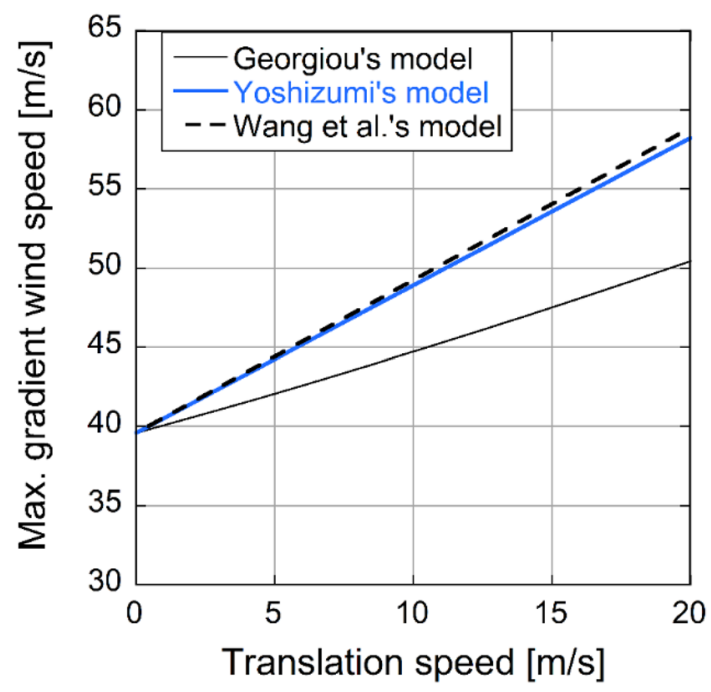

Fig. 17 Maximum gradient wind speed with variation in translation speed

Yoshizumi's model performs best at the $1000 \times 1000 \mathrm{~km}$ square domain. However, the increments of $L^{2}$-norms because of the domain extension are the lowest in Georgiou's model, suggesting that Georgiou's model performs best further away from the pressure center, as discussed in Subsection 5.1. 
Fig. $18 L^{2}$-norm of residuals in momentum conservation equations with variation in translation speed: a $200 \times 200 \mathrm{~km}$ square domain and $\mathbf{b} 1000 \times 1000 \mathrm{~km}$ square domain

Fig. $19 L^{2}$-norm of residuals in momentum conservation equations for a $1000 \times 1000 \mathrm{~km}$ square domain with variation in: a pressure difference, $\Delta p$, b Holland's $B$ parameter, c nominal radius to maximum wind, $r_{m}$, and $\mathbf{d}$ latitude at the pressure center, $\varphi_{0}$

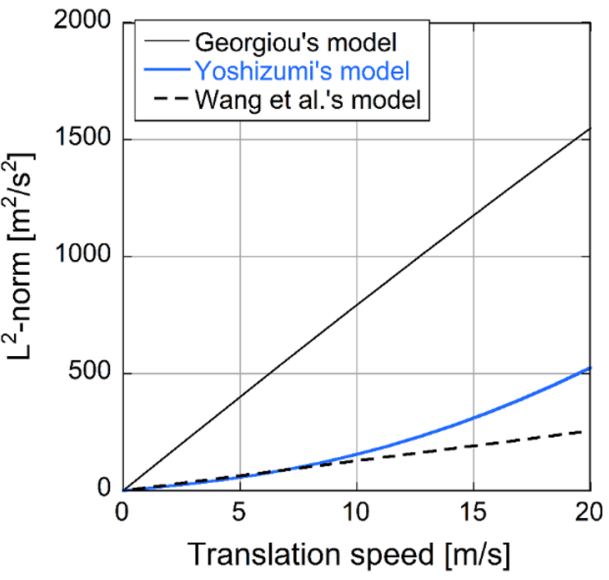

(a)

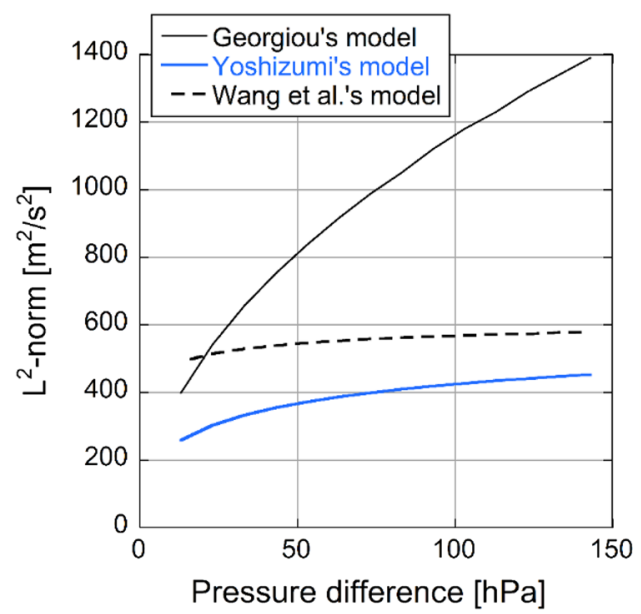

(a)

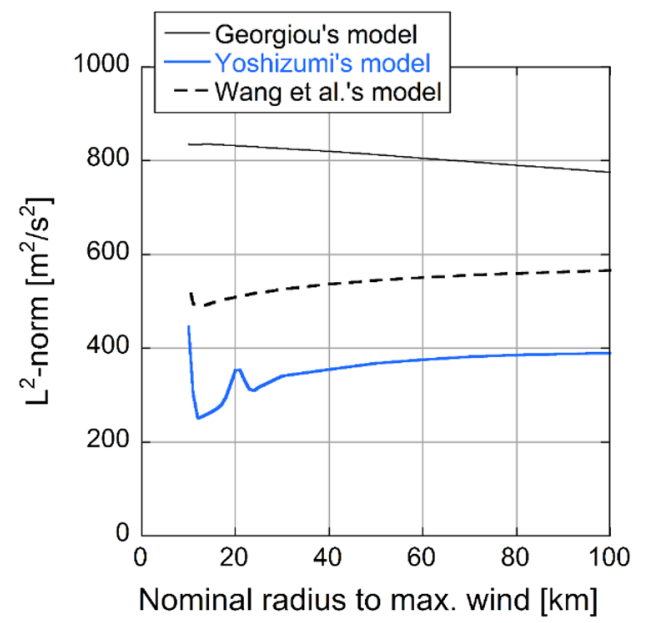

(c)

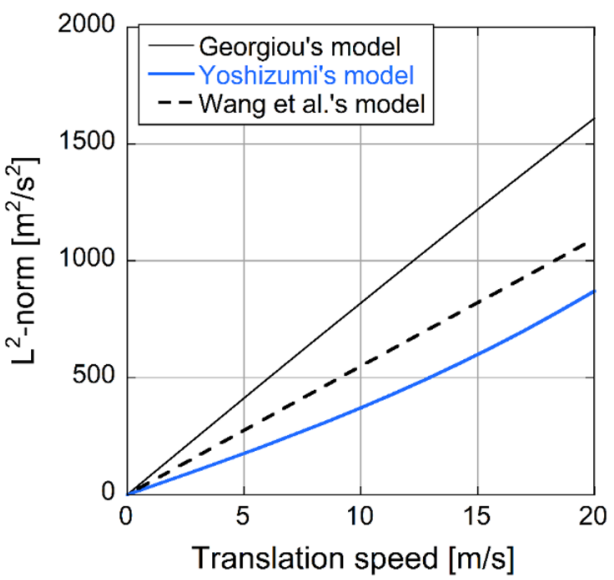

(b)

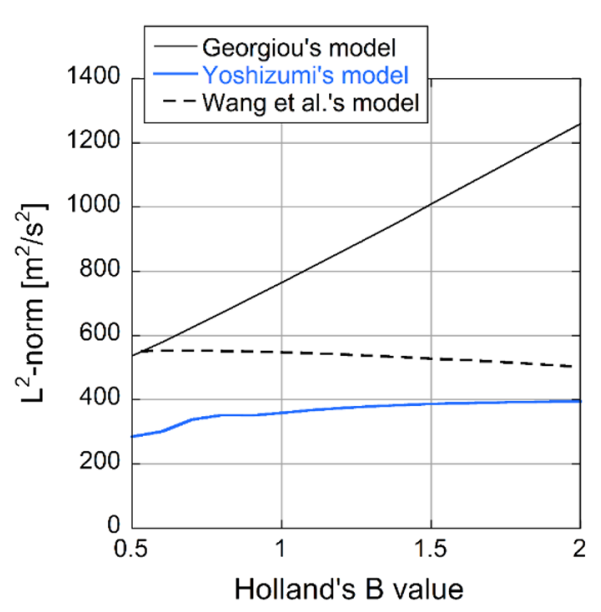

(b)

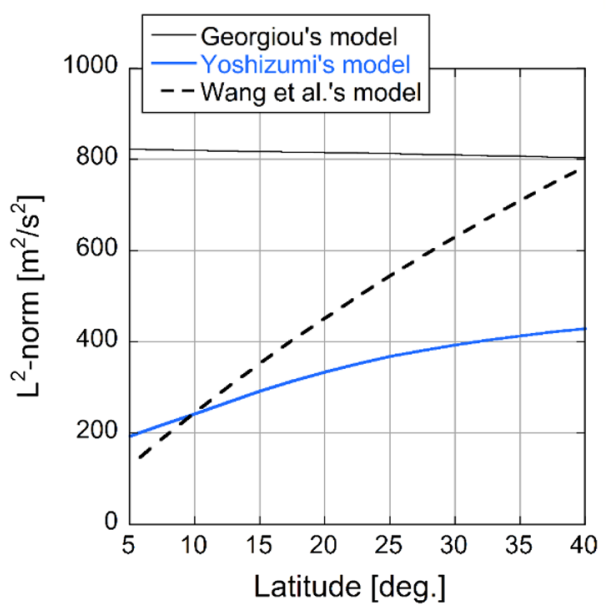

(d) 


\subsection{Sensitivity to other parameters}

In this subsection, we examine the sensitivities of the $L^{2}$-norm of the residuals to pressure difference, $\Delta p$, Holland's $B$ parameter, nominal radius to maximum wind, $r_{m}$, and latitude at the pressure center, $\varphi_{0}$. The sensitivity analysis was individually performed in a $1000 \times 1000 \mathrm{~km}$ square domain, keeping the conditions identical to those in Table 1 except for the individual parameter concerned. Figure 19 (a) to (d) shows variation of the $L^{2}$-norm of the residuals in accordance with each sensitivity parameter. It can be seen in Fig. 19(a) and (b) that the $L^{2}$-norms of Georgiou's model increase as the pressure difference, $\Delta p$, and Holland's $B$ parameter increase, while those of Yoshizumi's and Wang et al.'s models are quite insensitive to the parameters. Figure 19(d) indicates that the $L^{2}$-norm of Wang et al.'s model increases as the latitude at the pressure center, $\varphi_{0}$ increases, but it does not exceed that of Georgiou's model.

When the analyzed domain is reduced to a $200 \times 200 \mathrm{~km}$ square domain (results not shown), the $L^{2}$-norms of Yoshizumi's and Wang et al's models are closer to each other and quite insensitive to all the four parameters, staying in the range from 100 to $200 \mathrm{~m}^{2} / \mathrm{s}^{2}$. The $L^{2}$-norms of Georgiou's model for the $200 \times 200 \mathrm{~km}$ square domain are slightly smaller than those for the $1000 \times 1000 \mathrm{~km}$ square domain shown in Fig. 19(a) to (d).

\section{Conclusions}

To examine the validity of three gradient wind models used or proposed by Georgiou [14], Yoshizumi [19], and Wang et al. [12] for a translating tropical cyclone, the residuals of the momentum conservation equations for the three gradient wind fields were quantitatively evaluated for a specific cyclone condition. The sensitivities to translation speed, $|\boldsymbol{C}|$, pressure difference, $\Delta p$, Holland's $B$ parameter, nominal radius to maximum wind, $r_{m}$, and latitude at the pressure center, $\varphi_{0}$ were also analyzed to assess their effects on the $L^{2}$-norm of the residuals. The $L^{2}$-norms of the residuals showed that Wang et al.'s model performed best mainly in the vicinity of the pressure center, while Yoshizumi's model generally performed as well as Wang et al.'s model in the near-center region and best over a large domain. It was confirmed that these performances of the three models were largely consistent with the model validation results using the observation data of Hurricanes Emily (19 July 2005) and Wilma (24 October 2005), archived in $\mathrm{H}^{*}$ WIND [20].

The relative frequency distributions of the gradient wind speed of the three models for the specific cyclone condition indicated that the high wind speed features of Yoshizumi's model and Wang et al.'s model were very close, while Georgiou's model tended to underestimate wind speed in comparison with the other models in the high wind speed range. It was also shown that the maximum wind speed of Georgiou's model was lower than those of the other models, and the deviation became clearer as the translation speed and the intensity (pressure difference) of a tropical cyclone increased.

The curvature radii of streamlines and path lines were evaluated to analyze the wind field features of the three gradient wind models. The results indicated that the larger maximum wind speeds of Wang et al.'s model and Yoshizumi's model with lower residuals were due to the asymmetric distribution of the curvature radius of the streamline. In contrast, the curvature radius of the streamline in Georgiou's model was restricted to a symmetrical distribution. These different streamline features explained the different wind speed features among the three models.

In summary, our findings suggest that Wang et al.'s model or Yoshizumi's model would be preferable for use as a gradient wind model in applications for conservative wind-resistant design and conservative wind risk estimates.

Acknowledgements We would like to acknowledge NOAA (National Oceanic and Atmospheric Administration), HRD (Hurricane Research Division), AOML (Atlantic Oceanographic and Meteorological Laboratory) for enabling us to use the data of the Tropical Cyclone Observing System, $\mathrm{H}^{*}$ WIND (https://storm.aoml.noaa.gov/hwind/index .html). We also thank Leonie Seabrook, PhD, from Edanz Group (https://en-author-services.edanz.com/ac) for editing a draft of this manuscript.

Authors Contributions YE developed the computational code and performed numerical analysis, and then $\mathrm{YH}$ and $\mathrm{MN}$ reviewed the code and the numerical results for confirmation. YH reviewed previous research to identify the originality of the present paper. MN provided information to initiate the present research. YE prepared most of the main text, the figures and the tables, and then $\mathrm{YH}$ and $\mathrm{MN}$ reviewed the draft and provided valuable comments to finalize the manuscript.

Funding Internal funding allocated at discretion of CRIEPI (Central Research Institute of Electric Power Industry) was used for the research reported in this paper.

\section{Declarations}

Conflicts of interest The authors declare that they have no conflict of interest.

Availability of data and material All the data reported in this paper are available from the authors.

Code availability All calculations were done with the computational code developed by the authors. 
Open Access This article is licensed under a Creative Commons Attribution 4.0 International License, which permits use, sharing, adaptation, distribution and reproduction in any medium or format, as long as you give appropriate credit to the original author(s) and the source, provide a link to the Creative Commons licence, and indicate if changes were made. The images or other third party material in this article are included in the article's Creative Commons licence, unless indicated otherwise in a credit line to the material. If material is not included in the article's Creative Commons licence and your intended use is not permitted by statutory regulation or exceeds the permitted use, you will need to obtain permission directly from the copyright holder. To view a copy of this licence, visit http://creativecommons .org/licenses/by/4.0/.

\section{References}

1. Vickery PJ, Skerlj PF, Twisdale LA (2000) Simulation of hurricane risk in the U.S. using empirical track model. J Wind Eng Ind Aerodyn 126:1222-1237

2. Vickery PJ, Wadhera D, Twisdale LA, Lavell FM (2009) U.S. hurricane wind speed risk and uncertainty. J Struct Eng 135:301-320

3. Vickery PJ, Masters FJ, Powell MD, Wadhera D (2009) Hurricane hazard modeling: The past, present, and future. J Wind Eng Ind Aerodyn 97:392-405

4. Powell MD, Soukup G, Cocke S, Gulati S, Morisseau-Leroy N, Hamid S, Dorst N, Axe L (2005) State of Florida hurricane loss projection model: Atmospheric science component. J Wind Eng Ind Aerodyn 93:651-674

5. Snaiki R, Wu T (2020) Revisiting hurricane track model for wind risk assessment. Struct Safety 87:102003

6. Meng Y, Matsui M, Hibi K (1995) An analytical model for simulation of the wind field in a typhoon boundary layer. J Wind Eng Ind Aerodyn 56:291-310

7. Meng Y, Matsui M, Hibi K (1997) A numerical study of the wind field in a typhoon boundary layer. J Wind Eng Ind Aerodyn 67\&68:437-448

8. Vickery PJ, Skerlj PF, Steckley AC, Twisdale LA (2000) Hurricane wind field model for use in hurricane simulations. J Struct Eng 126:1203-1221

9. Vickery PJ, Wadhera D, Powell MD, Chen Y (2009) A hurricane boundary layer and wind field model for use in engineering applications. J Appl Meteor Climatol 48:381-405

10. Snaiki R, WuT (2017) A linear height-resolving wind field model for tropical cyclone boundary layer. J Wind Eng Ind Aerodyn 171:248-260

11. Snaiki R, Wu T (2020) An analytical model for rapid estimation of hurricane supergradient winds. J Wind Eng Ind Aerodyn 201:104175
12. Wang C, Zhang H, Feng K, Li Q (2017) A simple gradient wind field model for translating tropical cyclones. Nat Hazards 88:651-658

13. Fang P, Ye G, Yu H (2020) A parametric wind field model and its application in simulating historical typhoons in the western North Pacific Ocean. J Wind Eng Ind Aerodyn 199:104131

14. Georgiou PN (1986) Design Wind speeds in tropical cycloneprone regions. Digitized Theses 1523. https://ir.lib.uwo.ca/digit izedtheses/1523

15. Pei B, Pang W, Testik FY, Ravichandran N, Liu F (2014) Mapping joint hurricane wind and surge hazards for Charleston, South Carolina. Nat Hazards 74:375-403

16. Fang G, Zhao L, Cao S, Ge Y, Pang W (2018) A novel analytical model for wind field simulation under typhoon boundary layer considering multi-field correlation and height-dependency. J Wind Eng Ind Aerodyn 175:77-89

17. Wu F, Huang G (2019) Refined empirical model of typhoon wind field and its application in China. J Struct Eng 145:04019122

18. Brill KF (2014) Revisiting an old concept: the gradient wind. Mon Weather Rev 142:1460-1471

19. Yoshizumi S (1968) On the asymmetry of wind distribution in the lower layer in typhoon. J Meteorol Soc Jpn 46:153-159

20. Powell MD, Houston SH, Amat LR, Morisseau-Leroy N (1998) The HRD real-time hurricane wind analysis system. J Wind Eng Ind Aerodyn 77 \& 78:53-64

21. Holland GJ (1980) An analytic model of the wind and pressure profiles in hurricanes. Mon Weather Rev 108:1212-1218

22. Vickery PJ, Wadhera D (2008) Statistical models of Holland pressure profile parameter and radius to maximum winds of hurricanes from flight-level pressure and $\mathrm{H}^{*}$ Wind data. J Appl Meteor Climatol 47:2497-2517

23. Holland GJ, Belanger JI, Fritz A (2010) A revised model for radial profiles of hurricane winds. Mon Weather Rev 138:4393-4401

24. Hu K, Chen Q, Kimball SK (2012) Consistency in hurricane surface wind forecasting: an improved parametric model. Nat Hazards 61:1029-1050

25. Das $Y$ (2018) Parametric modeling of tropical cyclone wind fields in India. Nat Hazards 93:1049-1084

26. Holton J, Hakim G (2012) An introduction to dynamic meteorology, 5th edn. Academic Press, Cambridge

27. Fujita T (1952) Pressure distribution within a typhoon. Geophys Mag 23:437-451

28. Theisel $H$ (1998) Visualizing the curvature of unsteady 2D flow fields. Proc. of the 9th Eurographics Workshop on Visualization in Scientific Computing:47-56

Publisher's Note Springer Nature remains neutral with regard to jurisdictional claims in published maps and institutional affiliations. 